\title{
Nanodiamond Films for Applications in Electrochemical Systems
}

\author{
A. F. Azevedo, M. R. Baldan, and N. G. Ferreira \\ LAS, Instituto Nacional de Pesquisas Espaciais (INPE), CP 515, 12227-010 São José dos Campos, SP, Brazil
}

Correspondence should be addressed to A. F. Azevedo, adriana@las.inpe.br

Received 29 March 2011; Accepted 21 May 2011

Academic Editor: Yasuaki Einaga

Copyright ( 12012 A. F. Azevedo et al. This is an open access article distributed under the Creative Commons Attribution License, which permits unrestricted use, distribution, and reproduction in any medium, provided the original work is properly cited.

\begin{abstract}
The purpose of the present paper is to give an overview on the current development status of nanocrystalline diamond electrodes for electrochemical applications. Firstly, we describe a brief comparison between the general properties of nanocrystalline diamond (undoped and boron-doped) and boron-doped microcrystalline diamond films. This is followed by a summary of the nanodiamond preparation methods. Finally, we present a discussion about the undoped and boron-doped nanocrystalline diamond and their characteristics, electrochemical properties, and practical applications.
\end{abstract}

\section{Introduction}

Diamond nanocrystal is a topic of considerable interest in the scientific community, as properties of these systems are expected to retain a large extent of singular characteristics concerning polycrystalline diamond films [1]. The first reference related to these materials as "nanocrystalline" was presented in the Workshop on Diamond Thin Films in 1990 [2]. In 1994, Gruen and coworkers have reported that the growth of "fine-grained" or nanocrystalline diamond (NCD) films was obtained by Chemical Vapor Deposition (CVD) under hydrogen-poor and argon/carbon-rich conditions [3-5]. And, in 1999, this new material was reviewed under the label of "Nanocrystalline-Diamond Films" [6].

As a class, NCD films cover a wide variety of materials ranging from films with properties approaching to single crystal diamond to others which are useful for specialized applications. In fact, there are intrinsic electrochemical properties of diamond that are independent of the grain size (nano or micro), unequivocally distinguishing them from other commonly used $\mathrm{sp}^{2}$-bonded carbon electrodes. These properties are (i) a low and stable background current; (ii) excellent structural and morphological stability at high temperatures and current density; (iii) good responsiveness for several aqueous and nonaqueous redox analytes without any conventional pretreatment; (iv) long-term response stability; (v) optical transparency in the UV/Vis and IR regions of the electromagnetic spectrum, useful properties for spectroelectrochemical measurements [7].
However, when the size of the structure is decreased, the surface/volume ratio increases considerably and the surface phenomena predominate over the chemistry and physics in the bulk. Thus, there are some specific properties for the NCD films that differentiate them from microcrystalline. In Table 1 are shown some of the differences between NCD (undoped and boron-doped) and boron-doped microcrystalline diamond (BDD).

Thus, there are important features of crystalline materials that need to be well understood in order to improve their application efficiency in a wide range of areas such as mechanics, biomedicine, electrochemistry, and electronics, among others.

\section{The Preparation Methods of Nanodiamond Films}

The main route towards nanocrystalline diamond films is to use standard techniques to grow polycrystalline diamond films on different substrates [16-19], for example, microwave plasma [20-29] or hot filament [30-36]. The growth of nanometric films may be performed by changing some growth parameters, such as, the application of negative bias on the substrate [37-40], the increase of the methane concentrations [41-45] or by the addition of noble gas to the precursor mixture' $[10,46,47]$.

The gas mixture, with a high percentage of $\mathrm{CH}_{4}$ in $\mathrm{H}_{2}$ (5$20 \%$ ), provides a type of NCD morphology called cauliflower 
TABLE 1: A comparison of the some properties of the NCD and BDD.

\begin{tabular}{lccc}
\hline PROPERTY & NCD & BDD & References \\
\hline working potential window & 2.5 to $3.0 \mathrm{~V}$ & 3.0 to $3.5 \mathrm{~V}$ & {$[7-11]$} \\
conductivity & undoped or doped & only doped & {$[1,6,8,9]$} \\
roughness & $60-170$ & high & {$[1,10,11]$} \\
$\Delta E_{p}(\mathrm{mV})-\mathrm{Fe}(\mathrm{CN})_{6}{ }^{-3 /-4}$ & high & 60 to 80 & {$[7,11-14]$} \\
Effective surface area & & low & {$[15]$} \\
\hline
\end{tabular}

or ballas type $[48,49]$. Presumably the higher percentage of $\mathrm{CH}_{4}$ in $\mathrm{H}_{2}$ increases the twinning, and the non-diamond carbon incorporation thereby reducing the grain size [50]. Thus these NCD films can be grown without an appreciable increase of the roughness on growth surface, but at the cost of increasing the nondiamond component of the film (up to $50 \%$ nondiamond carbon).

The most used noble gas has been argon with concentrations above 70 vol. $\%[19,22,23,42-44,51]$. It promotes an increase of $\mathrm{CH}_{3}$ and $\mathrm{C}_{2}\left(\right.$ and/or $\left.\mathrm{C}_{2} \mathrm{H}\right)$ radical amounts close to the substrate surface which determines the growth morphology $[6,31]$. Originally, it was suggested that the $\mathrm{C}_{2}$ radical played an important role in the growth mechanism [6]. However, recent works have shown that the concentration of $\mathrm{CH}_{3}$ and $\mathrm{C}_{2} \mathrm{H}$ are much greater than $\mathrm{C}_{2}$, and these species may be more important growth precursors than $\mathrm{C}_{2}$ under typical nanocrystalline deposition conditions $[30,31,52]$.

In general, the other advantage of nanocrystalline diamond films is the possibility of deposition on different kind of substrates. However, two important regards must be considered when selecting a substrate: (i) tolerance of the high deposition temperature (1000-1200 K), and (ii) similarity in the thermal expansion coefficient with that of diamond $\left(1.1 \times 10^{-6} \mathrm{~K}^{-1}\right)$.

In relation to doped NCD films, they may be grown by adding nitrogen or boron in growth mixture mentioned above to obtain n-type or p-type semiconductor materials, respectively [1]. Boron is the most successful and widely used acceptor in diamond; and the doping can be achieved by adding substances as diborane, trimethyl borane, and boron trioxide. This is because of boron has a low charge carrier activation energy of $0.37 \mathrm{eV}$ [53]. At low doping levels, the diamond acts as an extrinsic semiconductor. At high doping levels the material acts as a semimetal. The success of such a doping will be largely dependent on the dopant position within the films and the nature of the bonding of the dopant atoms to the surrounding of the carbon atoms. The possibility of $\mathrm{n}$ - and p-type diamond doping $[54,55]$ opens the door for a generation of bipolar devices, such as a diamond $\mathrm{p}-\mathrm{n}$ junction reported by Koizumi et al. [56]. Other dopants have also been tried, such as sulfur and arsenic [57]; however, no systematic results have been obtained so far.

Therefore, this paper will present a short, up-to-date and compact review covering nearly all aspects of nanodiamond electrodes. In next topic will be reported the properties, characterizations, and applications of undoped and borondoped nanocrystalline diamond electrodes separately.

\section{Undoped and Boron-Doped Nanocrystalline Diamond Electrodes for Electrochemical Applications}

New materials research for electrochemical applications has been a challenge in the last few years. The use of diamond films in electrochemistry is relatively a new field of research. The first article in the field was published in 1983 by Iwaki et al. [58], but the field was really initiated by the important article from Pleskov et al. [59] in 1987.

However, the doping is not a unique way to make dielectric diamond conducting. The NCD structures have the conductance caused by the same structural defects, and also due to continuous network formed by the amorphous carbons that are incorporated in the intercrystallite boundariesduring the film growth process [6]. Gruen [6] has observed that when the crystalline size is reduced to nanometer scale, the percentage of carbon atoms located at grain boundary increases drastically with the decrease of grain size. Clearly, the magnitude of the effects on properties is directly proportional to the fraction of carbon atoms residing at the grain boundary. He has concluded that the conduction occurs via $\pi$ states in the grain boundary and anything chemically or electrochemically that alters the grain boundary bonding influences the electrical conductivity, and as a consequence, the electrical properties of NCD.

Finally, we will report the characteristics, properties and applications of two types of nanocrystalline diamond electrodes, undoped and boron-doped.

3.1. Undoped Nanocrystalline Diamond Electrodes. As mentioned previously, the undoped $\mathrm{NCD}$ films are usually deposited from $\mathrm{CH}_{4} / \mathrm{H}_{2}$ or $\mathrm{CH}_{4} / \mathrm{H}_{2} / \mathrm{Ar}$ gas mixture. Nowadays, high quality nanocrystalline and polycrystalline electrodes can be obtained from different commercial sources. Particularly, the film shown in Figure 1 was obtained in Diamond Laboratory of LAS/INPE (São Paulo, Brazil). It was prepared by hot filament chemical vapor deposition (HFCVD) technique on a silicon substrate using a gas mixture of $\mathrm{CH}_{4} / \mathrm{H}_{2} / \mathrm{Ar}$ with a flow of $0.5 / 9.5 / 90 \mathrm{sccm}$ [44]. The value of argon concentration is very close to values studied by other authors that obtained the smallest grains and better films with argon concentrations at or above 90 vol.\% using HFCVD [60, 61] or microwaves system $[28,62]$. This film presented a uniform morphology with grains around $50 \mathrm{~nm}$. The micrograph obtained by Field Emission Gun Scanning Electron Microscopy (FEG-SEM) was performed using Zeiss-SUPRA 35 equipment. 


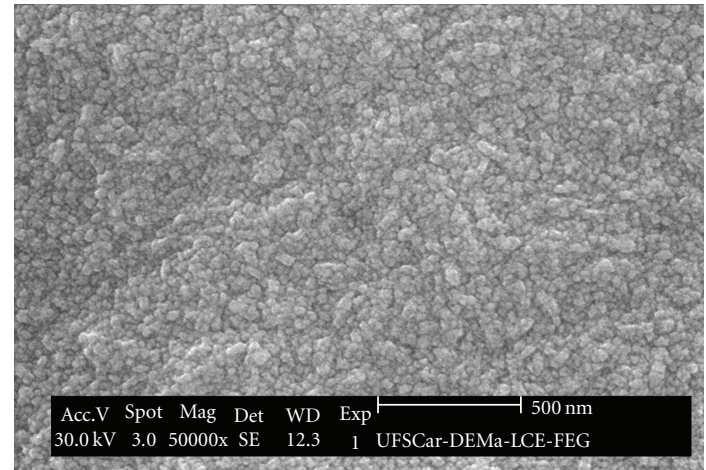

FIgure 1: FEG-SEM image of undoped NCD film grown on a silicon substrate.

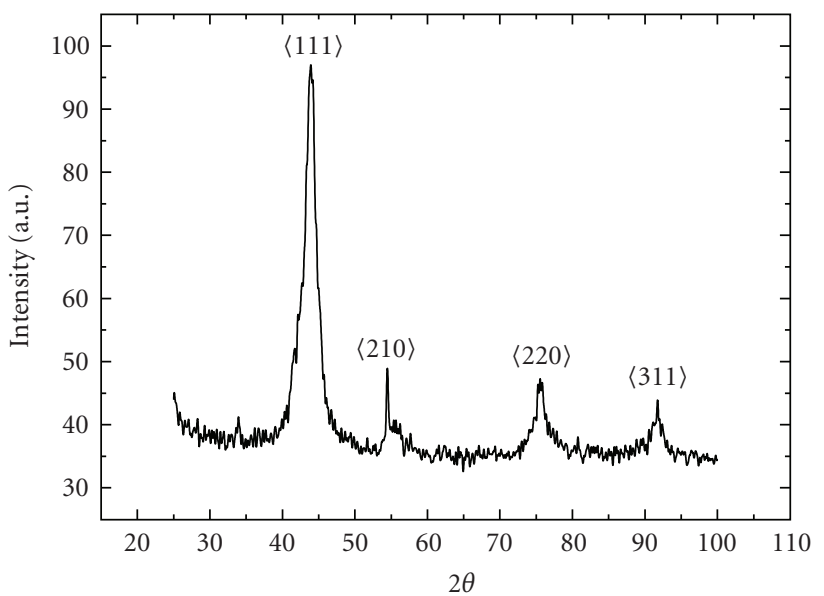

FIGURE 2: X-ray diffraction spectrum of undoped NCD film grown on a silicon substrate.

The nanodiamond crystallinity was investigated by Xray diffraction (XRD) using a high resolution Philips diffractometer, X'Pert model, with the $\mathrm{CuK}_{\alpha 1}$ radiation $(\lambda$ $=1.54 \mathrm{~A}$ ) in grazing incident mode with an incident angle of $5^{\circ}$. XRD pattern of film is shown in Figure 2. The XRD spectrum of the NCD film is dominated by the peaks at $43.9^{\circ}$, $54.57^{\circ}, 75.3^{\circ}$, and $91.5^{\circ}$ corresponding to the $\langle 111\rangle,\langle 210\rangle$, $\langle 220\rangle$, and $\langle 311\rangle$ diamond diffraction peaks that evidence the presence of crystalline diamond [63]. It should be noted that no peaks associated with graphite or features related to amorphous carbon could be identified in this film.

Raman spectroscopy has become one of the most used tools for the characterization of disordered polycrystalline graphitic carbons. This technique is simple, not destructive and it is possible to determine the quality of diamond film by the ratio of $\mathrm{sp}^{3} / \mathrm{sp}^{2}$ carbon bonds [64]. This film was analyzed by micro-Raman scattering spectroscopy (Renishaw microscope system 2000) using the $514.5 \mathrm{~nm}$ line of an argon ion laser taking the spectra covering the range from 1000 to $1800 \mathrm{~cm}^{-1}$ as shown in Figure 3 .

The film spectrum is characteristic of NCD, showing a broad peak at $1345 \mathrm{~cm}^{-1}$ (D band) that represents a zoneedge Alg mode due to the disorder and a G peak centered

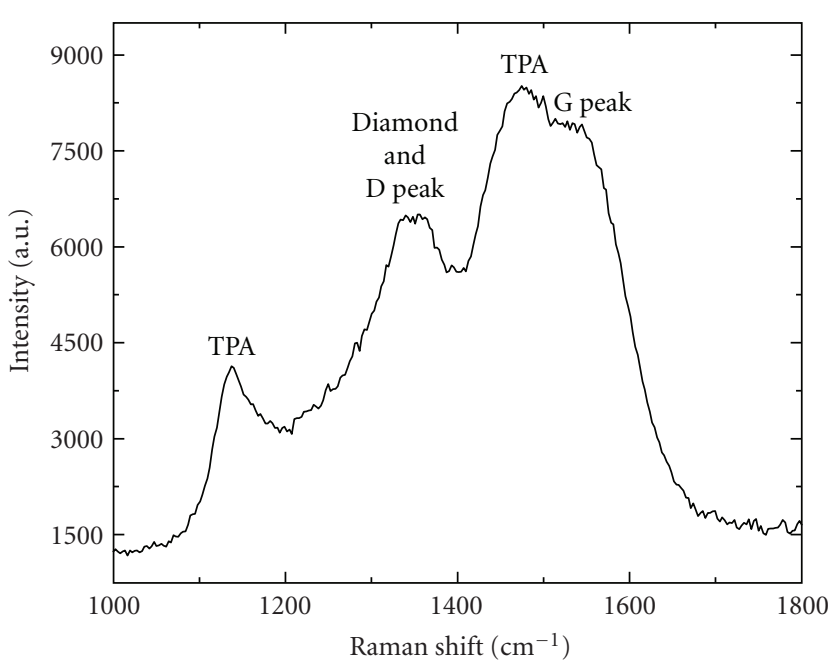

Figure 3: Raman spectrum of undoped NCD film grown on a silicon substrate.

at about $1550 \mathrm{~cm}^{-1}$ that corresponds to graphite [65]. The diamond peak at about $1332 \mathrm{~cm}^{-1}$, not observed in visible Raman spectra of NCD films, is generally obscured by the overlapping of D peak, which is more sensitive to nondiamond phases. According to Ferrari and Robertson [66], the D peak is due to the breathing modes of Alg symmetry involving phonons near the $\mathrm{K}$ zone boundary while the $\mathrm{G}$ peak is due to the bond stretching of all pairs of $\mathrm{sp}^{2}$ atoms in both rings and chains [67]. This mode is forbidden in perfect graphite and only becomes active in the presence of disorder. The Raman spectrum also exhibited two bands at 1150 and $1490 \mathrm{~cm}^{-1}$. This pair of peaks has already been discussed as the transpolyacetylene (TPA) segments at the grain boundaries of NCD surface [66].

Taking into account that the nanocrystalline grains are mainly surrounded by graphitic and oxygenated carbon forms, XPS spectrum should reveal a surface enrichment of graphitic, oxygen bonded, and dangling carbon components with respect to the diamond one. This suggestion is adequately confirmed by the analysis of C1s XPS spectrum of this film. A better fitting of the experimental data was obtained assuming the concomitant presence of distinct groups of chemical species, emerging at separate Binding Energies (BE) maxima, in accordance with the analyzed spectrum. As a matter of fact, the residual curve suggests that this result was affected by minor errors. Moreover, the relevant physical parameters related to each component, for example, the mixing Gaussian factor, $\chi^{2}$ and FWHM, are meaningful, thus allowing a reliable qualitative and quantitative XPS analysis.

The C1s XPS film spectrum is shown in Figure 4. The C1s peak evidenced the presence of several components, including graphitic (or $\mathrm{sp}^{2}$-like carbon), diamond (or $\mathrm{sp}^{3}$ hybridized carbon) species and, to a less variable extent, oxidation products containing oxygen - carbon bonds. Considering the fitting of data in Figure 4, the most intense peak (II), centered at $284.1 \mathrm{eV}$, may be attributed to the bulk diamond component (sp3 $\mathrm{C}-\mathrm{C})$ and the less intense 


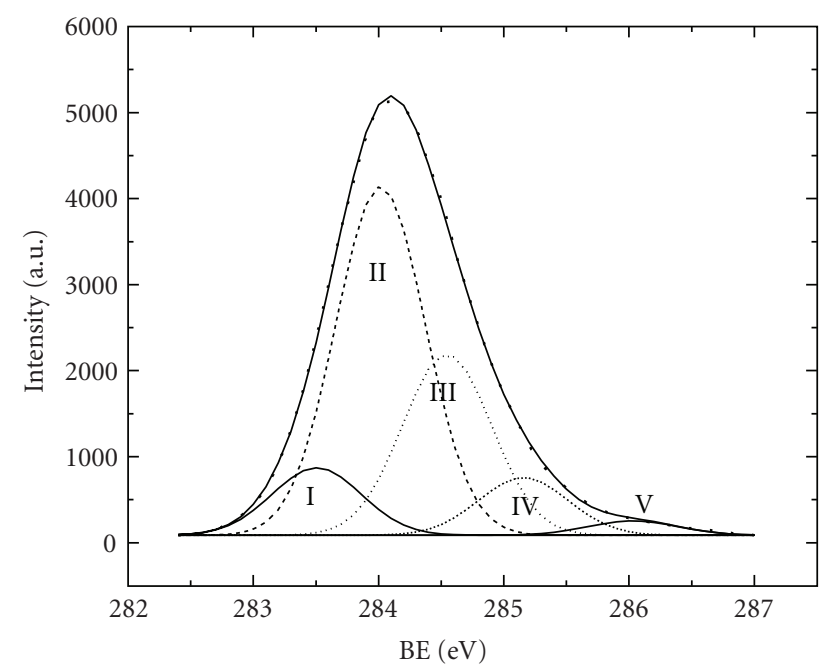

FIGURE 4: C1s XPS spectra of undoped NCD film grown on a silicon substrate.

component (I), shifted by $-0.5 \mathrm{eV}$ with respect to diamond peak, may be assigned to graphitic carbon species (sp2 C-C). The peak (III) corresponds to $\mathrm{C}-\mathrm{H}$ and the two remaining peaks, centered at higher $\mathrm{BE}$ values, could be reasonably assigned to alcoholic (peak IV) and carbonyls (peak V) functional groups, respectively [68].

The electrochemical characteristics of this undoped NCD electrode, immersed in aqueous electrolyte solution, are very close to be observed by others authors. Three electrodes, (work electrode, counter electrode and reference electrode) inside of a single-compartment electrochemical cell were used in this study. The electrodes were not submitted to surface pretreatment before electrochemical measurements and their geometric area in contact with the electrolyte was $0.10 \mathrm{~cm}^{2}$. The platinum coil and $\mathrm{Ag} / \mathrm{AgCl}$ electrodes were used as counter and reference electrodes, respectively. Solutions were deoxygenated with $\mathrm{N}_{2}$ for at least 20 min prior to and blanketed with the gas during the measurements. The treatments of systems called quasireversible is associated to reactions that show electron's transfer kinetic limitations and consequently, for these systems, reverse reactions have to be considered [69]. In this way, NCD electrode was analyzed by the quasi-reversibility criteria: the separations between the anodic and cathodic peaks $\left(\Delta E_{p}\right)$ are larger than $59 / n \mathrm{mV}$ (where $n=1$ is the number of electrons involved in the reaction).

In Figure 5 are shown (a) the Cyclic Voltammetric (CV) i-E curve in $0.5 \mathrm{~mol} \mathrm{~L}^{-1} \mathrm{H}_{2} \mathrm{SO}_{4}\left(\nu=0.1 \mathrm{~V} \mathrm{~s}^{-1}\right)$ and (b) electrochemical response from a curve obtained in $1 \mathrm{mmol} \mathrm{L}^{-1}$ of ferrocyanide $+0.1 \mathrm{~mol} \mathrm{~L}^{-1} \mathrm{KCl}\left(\nu=10 \mathrm{mV} \mathrm{s}^{-1}\right)$ for the typical film obtained in our laboratory. CV measurements were carried out at room temperature using a potentiostat Omnimetra Instruments PG 3901.

Electrochemistry response for the NCD film showed a low capacitance and stable background currents. This result is attractive features of diamond for potentially improved signal-to-background in electrochemical assays. The curve also revealed a working potential window around $2.6 \mathrm{~V}$ versus $\mathrm{Ag} / \mathrm{AgCl}$ where the oxidation water begins at $1.8 \mathrm{~V}$ and the reduction water begins at $-0.8 \mathrm{~V}$ (ibaseline $<2 \mu \mathrm{Acm}^{-2}$ ). This value was very close to the results observed by Hian et al. [70], ca. 2.5 V versus SCE, and Foord and Hu [71], ca. $2.8 \mathrm{~V}$ versus SCE. Well-defined oxidation (ca. $0.38 \mathrm{~V}$ ) and reduction (ca. $0.18 \mathrm{~V}$ ) peaks of the same current magnitude are seen for NCD electrode with a peak potential separation, $\Delta E_{p}$, of $200 \mathrm{mV}$. The electrode reactions kinetics for this couple are strongly influenced by the amount of exposed edge planes on $\mathrm{sp}^{2}$-bonded carbon as well as the surface cleanliness [72]. Granger and Swain. [73] have shown that surface carbon-oxygen functionalities on microcrystalline diamond significantly influence $\Delta E_{p}$ with increasing oxygen content causing an increase in the peak potential separation. According to them, the oxygen blocks the surface site that is involved in the reaction on the film surface. Apparently, this affirmation can also be applied to this nanodiamond film.

Gruen et al. $[12,74]$ have demonstrated that smooth and high-quality diamond films can be produced using fullerene $\left(\mathrm{C}_{60}\right)$ and $\mathrm{CH}_{4}$ precursors, taking into account the gas mixture. This result was obtained in argon microwave plasmas without the addition of $\mathrm{H}_{2}$. Diamond films produced in this way are nanocrystalline, smooth $(20 \pm 50 \mathrm{~nm}$ rms surface roughness typically), electrochemically active (i.e., conductive), and highly reactive. The working potential window for the films is ca. $3.0 \mathrm{~V}$ versus SCE and is larger than the ca. $2.5 \mathrm{~V}$ window observed for freshly polished glassy carbon. The films also exhibited reasonably good voltammetric responses for $\mathrm{Fe}(\mathrm{CN})_{6}{ }^{-3 /-4}$ and $\mathrm{Ru}\left(\mathrm{NH}_{3}\right)_{6}{ }^{+2 /+3}$, with $\Delta E_{p}$ values of 167 and $90 \mathrm{mV}$, respectively. They concluded that the larger $\Delta E_{p}$ at the nanocrystalline film may be related to the presence of surface oxides. These results confirm that the surface cleanliness is important, as well as the electrolyte type and concentration [12].

In general, the porous materials are of scientific and technological interest because of their ability to interact with atoms, ions, and molecules not only at their surfaces, but throughout the bulk of the material. Not surprisingly, traditional applications of porous materials involve ion exchange, adsorption (for separation) and catalysis, and several of these benefits from the high order that can be achieved in solids such as zeolites. In the same way, the growth of microcrystalline diamond on porous silicon (PS) substrate has been studied with the objective of increasing the number of diamond nucleation sites, being a promising material for obtaining better crystalline structure and an excellent electrochemistry capacitor due to their large superficial area [75].

In this context, Ferreira et al. [36] have grown NCD films on a micrometric PS substrate to use as capacitor. The PS substrate was produced by anodic etching using n-type silicon wafers. From the micrographs in Figures 6(a) and 6(b), they observed nanograins with average size from 30 to $50 \mathrm{~nm}$ and uniform surface texture covered all the supports among the pores resulting in an apparent microhoneycomb structure.

$\mathrm{NCD} / \mathrm{PS}$ presented a work potential window at $3.0 \mathrm{~V}$ versus $\mathrm{Ag} / \mathrm{AgCl}$ and a large capacitive background current, 


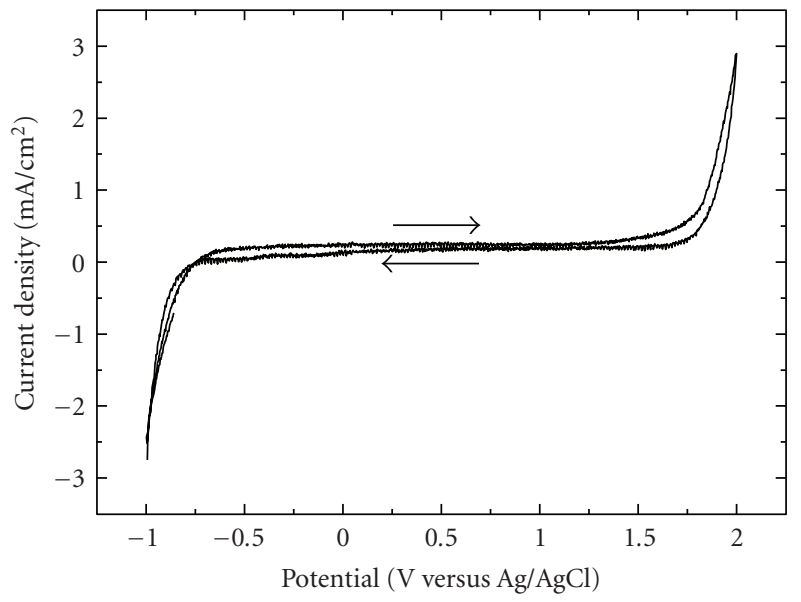

(a)

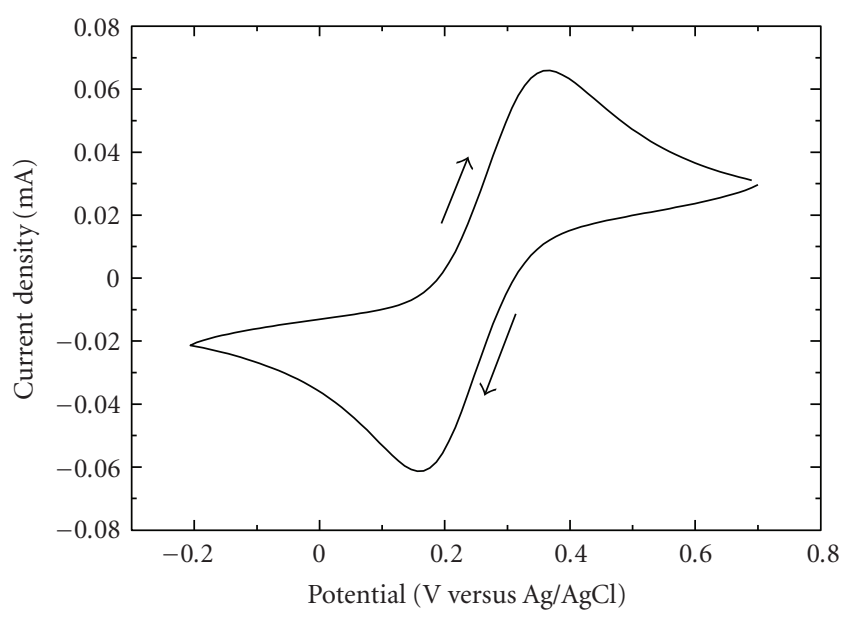

(b)

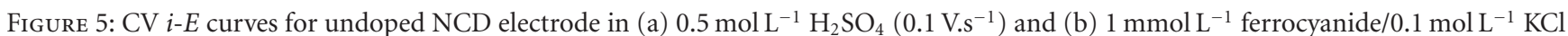
$\left(10 \mathrm{mV} . \mathrm{s}^{-1}\right)$, respectively.

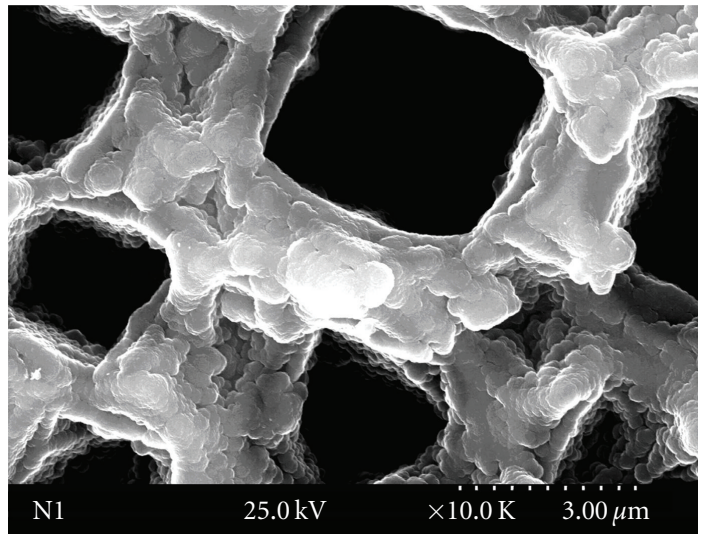

(a)

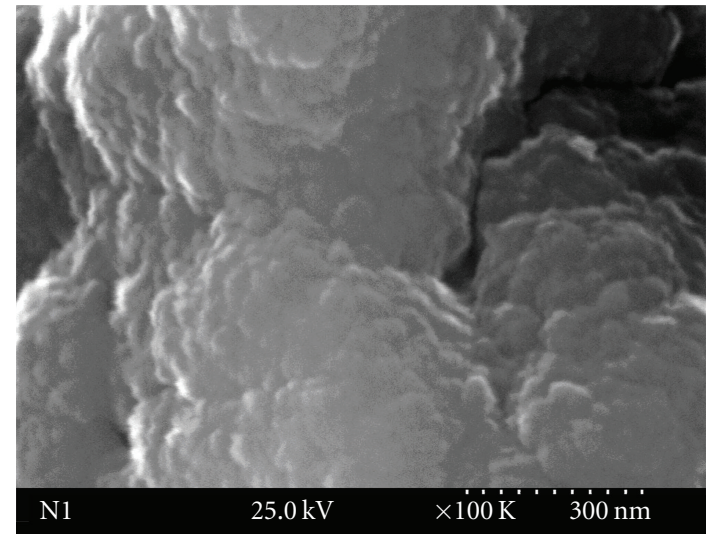

(b)

FIGURE 6: SEM images of undoped NCD grown on n-type PS sample. The magnification was increased from (a) to (b) for better visualization of nanograin.

mainly due to increase of electrode surface area as expected for such porous electrode. Taking into account the capacitor applications, they discussed that the double layer capacitive current for NCD/PS was 30 times larger than the asdeposited microcrystalline BDD electrodes. They evaluated the capacitance in the potential range of -0.5 up to $1.0 \mathrm{~V}$ versus $\mathrm{Ag} / \mathrm{AgCl}$ and showed that for $\mathrm{BDD}$ electrode; the values in this range were 20 and $40 \mu \mathrm{F} \mathrm{cm}^{-2}$. However, $\mathrm{NCD} / \mathrm{PS}$ electrodes presented superior capacitance in the same range from 230 to $990 \mu \mathrm{F} \mathrm{cm}^{-2}$ corresponding to an increase of around 25 times at $1.0 \mathrm{~V}$ versus $\mathrm{Ag} / \mathrm{AgCl}$. From all these results, they considered the possibility of NCD on PS substrates for electrochemical capacitor applications.

The use of silicon as a substrate for the diamond films growth is the most perfect due to their thermal expansion coefficients are very close. But for several practical applications the brittleness of silicon is forbidden, and then the metal substrates are used as an alternative. Beyond the mechanical resistance, another advantage is the possibility to produce large area electrodes up to the square meter range. The titanium is widely used in many technological applications, such as aeronautics, bioimplants, dental prostheses, and commercial electrodes. Therefore, the combination of diamond films with titanium substrates may expand the range of possible applications $[25,40,45,76]$. Hian et al. [70, $77,78]$ have deposited an adherent nanodiamond film on titanium rods substrates for electroanalysis application. After the film deposition, they compared the metal deposition and stripping processes with gold and copper at nanodiamond and BDD electrodes and concluded that the processes were faster and more efficient at nanodiamond electrodes. They mentioned that the nanodiamond films exhibit significant electrical conductivity due to the graphitic content and high concentration of grain boundaries in the material and offer advantages over BDD in terms of enhanced reactivity [70]. They also observed that the nucleation of gold appeared to be 
facile at edge sites, which are abundant on the nanodiamond surface. For the deposition and stripping of both gold and copper, a stripping efficiency (the ratio of electrodissolution charge to electrodeposition charge) of close to unity was detected even at low concentrations of analyte.

Braga et al. [79] have also shown to be possible to produce hybrid three-dimensional electrodes with NCD films on porous titanium ( $\mathrm{Ti}$ ) substrates. They used the power metallurgy technique to obtain the $\mathrm{Ti}$ substrates provided by interconnected and open porous among its volume. Electrochemical response revealed a working potential window around $3.3 \mathrm{~V}$ versus $\mathrm{Ag} / \mathrm{AgCl}$ and a $\Delta E_{p}=120 \mathrm{mV}$. In the case of the NCD/Ti electrode, the high value of $\Delta E_{p}$ may be attributed to the presence of a high amount of the $\mathrm{sp}^{2}$-bonded carbon and film roughness. They concluded that such electrode may be applied to different electrochemical applications due to the structural advantages of the metallic Ti structure, the porosity introduced in the bulk material, and chemical properties of the diamond.

Mani et al. [80] have obtained a new nanocomposite containing nanocrystalline diamond and an amorphous $\mathrm{sp}^{3}$ carbon phase that was synthesized by immersing a platinum wire substrate into the plasma. This material exhibited excellent electrochemical properties with wide potential window ( $>2.0 \mathrm{~V}$ in $\mathrm{H}_{2} \mathrm{SO}_{4}$ ) and high degree or reversibility for the dopamine redox couple ( $<100 \mathrm{mV}$ peak separation). In addition, the nanocomposite was mechanically rugged and chemically stable in a variety of acidic and basic environments and did not require any surface preparation or any additional ohmic contacts. They suggested that these nanocomposites could directly be used in several analytical, biomedical, waste remediation, and electrosynthesis applications.

3.1.1. Applications of Undoped Nanocrystalline Diamond Electrodes. The undoped nanodiamond electrodes can be used in different applications due to their electrochemical properties. Besides, in some cases, these electrodes can be modified in multiple paths to change their properties. However, most of them have been used as a biosensor.

The interaction between electrode surface and the analyte that will be analyzed is very important. According to Lawrence and Don [81], the surface of as-grown CVD diamond films is typically terminated with hydrogen atoms. The unpolar hydrogen-terminated surface gives the electrodes a hydrophobic nature, while oxygen-terminated surface gives a hydrophilic nature. Klauser et al. [82] have shown the importance of this interaction when investigated the effect of fetal bovine serum (FBS) on cell adhesion on surfaces of identical roughness and topography but varying the surface chemistries of NCD terminations (hydrogen, fluorine and oxygen terminations). Two different cell lines, porcine renal epithelial cells (LLC-PK1) and carcinoma cells (PANC1) were cultured on the NCD surfaces with and without $10 \%$ FBS in the growth medium. They concluded that the addition of FBS to the growth medium allowed cell adhesion on both hydrophilic and hydrophobic NCD surfaces. In contrast, in FBS-free medium, cell attachment could only be assessed on hydrophilic surfaces. Understanding basic cellsurface interactions on hydrophilic surfaces is complex, and mechanisms of direct cell attachment on hydrophilic surfaces are not as well investigated as protein-mediated cell-surface interactions. Furthermore, protein adsorption is dependent on surface wettability and therefore more degrees of freedom have to be considered. Anyway, NCD offers the possibility to generate cell growth substrates with well-defined surface properties.

Huang et al. [83] have also studied the influence of surface treatments in the immobilization of antibodies on nanodiamond for biosensor applications. They analyzed the anti-Salmonella and the anti-Staphylococcus aureus antibodies. The efficacy of antibody immobilization was evaluated by enzyme-linked immunosorbet assay (ELISA) and the bacterial binding efficiency was analyzed by SEM pictures. They concluded that the immobilization efficacy of both antibodies and bacterial binding efficiency on air plasma treated nanodiamond are better than those of the hydrogen plasma treated. The explanation for this is that the nanodiamond electrodes treated by air plasma had oxidized surfaces, consequently, is more hydrophilic. Thus, the contact between the hydrophilic antibody solution and the hydrophilic nanodiamond surfaces was enhanced.

Indeed, recent works have shown different applications to oxygen-terminated nanodiamond surfaces, including as transducer material for the detection of $\mathrm{pH}$ and penicillin concentration [84, 85]. Poghossian et al. [84] have developed a field-effect capacitive EDIS (electrolyte-diamondinsulator-semiconductor) structure as a platform for (bio) chemical sensing. According to them, in contrast to transistor structures, EDIS sensors are simple in layout and cost-effective in fabrication. Usually, no photolithographic process steps or complicated encapsulation procedures are required in case of the capacitive field-effect EDIS structure. Consequently, they characterized the NCD-based field-effect sensors by means of constant-capacitance method. The average $\mathrm{pH}$ sensitivity of the O-terminated NCD film was $40 \mathrm{mV} / \mathrm{pH}$. A low detection limit of $5 \mu \mathrm{M}$ and a high penicillin $\mathrm{G}$ sensitivity of $65-70 \mathrm{mV} /$ decade was obtained for an EDIS penicillin biosensor with the adoptively immobilized enzyme penicillinase. Finally, they proposed a model of the drift mechanism in EDIS sensors, as well as an immobilization of biomolecules (DNA and proteins) on NCD films for extending the biosensor capabilities of the EDIS platform.

Another possibility is to obtain modified nanodiamond electrodes, which can be performed by the deposition of layers of different chemistry or biological compounds, for biosensor device as studied by Rubio-Retama et al. [86] and Yang et al. [87]. Rubio-Retama et al. [86] have investigated the functionalization of NCD thin films with horseradish peroxidase (HRP). The electrochemical behavior of the modified NCD surface was characterized by impedance spectroscopy and CV. The proximity of HRP heme groups to the NCD surface allowed direct electron transfer between them. The heterogeneous electron-transfer constant for both processes was calculated to be $0.066 \mathrm{~s}^{-1}$, the charge-transfer coefficient $\alpha=0.49$, and the immobilized enzymatic layer about $2 \times 10^{-10} \mathrm{~mol} \mathrm{~cm}^{-2}$. The modified NCD electrode was used as a third generation biosensor for hydrogen peroxide 
determination showing a linear response in the $0.1-45 \mathrm{mmol}$ $\mathrm{H}_{2} \mathrm{O}_{2}$ range, at $+0.05 \mathrm{~V}$ versus $\mathrm{Ag} / \mathrm{AgCl}$. Thus, they concluded that the immobilized enzyme maintains its activity and good stability. These results confirmed that modified NCD electrodes could be used for in vivo applications or for optimizing clinical methodologies that are based on the measurement of hydrogen peroxide produced during the analytical process.

Meanwhile, Yang et al. [87] have shown that NCD thin films covalently modified with DNA oligonucleotides provide an extremely stable, highly selective platform in subsequent surface hybridization processes. They used a photochemical modification scheme to modify chemically the NCD surface, producing a homogeneous layer of amine groups that serve as sites for DNA attachment. After linking DNA to the amine groups, hybridization reactions with fluorescently tagged complementary and noncomplementary oligonucleotides showed no detectable non-specific adsorption, with extremely good selectivity between matched and mismatched sequences. Comparison of DNA-modified NCD film with other commonly used surfaces for biological modification, such as gold, silicon, glass, and glassy carbon, showed that diamond was unique in achieve a high stability and high sensitivity and while it also was compatible with microelectronics processing technologies.

In general, the use of carbon materials has promoted great interest for fuel cells and supercapacitor electrodes [88]. Also called electrochemical capacitor, they have been extensively studied due to the increasing demand for a new kind of electrical energy accumulators of long durability (over $10^{6}$ cycles) and high specific power (more than $10 \mathrm{~kW} / \mathrm{kg}$ ) [89]. Then, the study of new hybrid nanomaterials is very important for understanding and promoting new technologies in this area. Almeida et al. [90] have shown that the NCD formation on carbon fiber (CF) structures produces an innovative material, the diamond porous electrode, with a large surface area and high capacitive response. Furthermore, NCD grown directly on CF substrate promotes an electrode with low electric resistance, improving the device performance. In Figure 7 is showed the $\mathrm{CV}$ of NCD/CF electrode in $0.5 \mathrm{~mol} \mathrm{~L}^{-1} \mathrm{H}_{2} \mathrm{SO}_{4}$ solution at the scan rates of 100 and $10 \mathrm{mV} \mathrm{s}^{-1}$.

This result showed that the NCD/CF electrode has the characteristic behavior of an ideal capacitor with rectangular current-potential responses curves. As discussed by Chen et al. [91], using carbon nanotubes, the achievement of rectangular-shaped $\mathrm{CV}$ over a wide range of scan rate is the ultimate goal for electrochemical double-layer capacitors. This behavior is very important for practical applications when two contributions are assigned: a higher energy density due to the wide potential range and a higher power density associated to the scan rate increase. This behavior was confirmed by the inset in Figure 7 . The currents at $0.6 \mathrm{~V}$ were plotted as a function of scan rate, assuming that there is a contribution of non-Faradaic reactions at this potential. The plot of the NCF/CF electrode depicts a linear dependence with scan rate for the whole range studied up to $100 \mathrm{mV} \mathrm{s}^{-1}$. This result should also be pointed out since for an ideal capacitor, its capacitance is independent of the

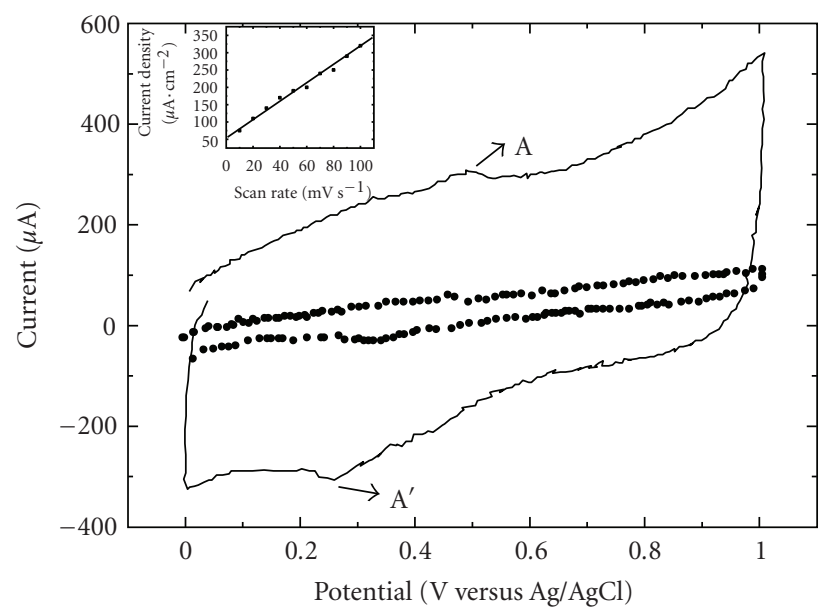

Figure 7: CV $i-E$ curves for NCD/CF electrode in $0.5 \mathrm{~mol} \mathrm{~L}^{-1}$ $\mathrm{H}_{2} \mathrm{SO}_{4}$ aqueous solution. Scan rate: $100 \mathrm{mV} \mathrm{s}^{-1}$ (solid line) and $10 \mathrm{mV} \mathrm{s}^{-1}$ (dash line).

frequency, so the charge stored by a capacitor is proportional to the imposed potential. Apparently, the pair of broad redox peaks ( $\mathrm{A}$ and $\mathrm{A}^{\prime}$ ) that appear in Figure 7 may be the oxidation/reduction of surface functional groups on $\mathrm{CF}$ substrate.

They also measured the specific capacity from the linear regression of the graph of current density in function of the scan rate (inset in Figure 7). The value for NCD/CF was $2.6 \mathrm{mF} \mathrm{cm}^{-2}$. Finally, they compared this value with other values reported in the literature. The best comparison with data already presented in the literature was the nanohoneycomb structures of the BDD films that were investigated by Yoshimura et al. [92]. Particularly, the specific capacity for a nanohoneycomb electrode $(60 \times 500 \mathrm{~nm})$ in an aqueous solution was $1.83 \mathrm{mF} \mathrm{cm}^{-2}$, which is lower but in the same order of magnitude for this NCF/CF electrode studied.

3.2. Boron-Doped Nanocrystalline Diamond Electrodes. A second type of nanodiamond electrodes which seems to become more important is a boron-doped nanocrystalline diamond (BDND). These films can be obtained using the same conditions of undoped-NCD film growth as mentioned previously. The doping can be reached by adding substances containing boron in the gas mixture. Rarely, the morphology is different from that shown for undoped-NCD. However it may vary slightly according to the experimental conditions, substrate used, and so forth [93-95]. In Figure 8 is shown the surface of BDND film grown on a silicon substrate obtained in Diamond Laboratory of LAS/INPE (São Paulo, Brazil). Scanning Electron Microscopy (SEM) image of BDND was performed using a JEOL JSM-5310 microscope system. It showed that the morphology is quite similar to that of unfaceted CVD ballas diamond, with grains tended to form agglomerates. These agglomerates have approximately $1.5 \mu \mathrm{m}$ of diameter with grains smaller than $30 \mathrm{~nm}$. NCD films with agglomerates grown on a silicon substrate were also reported by Yang et al. [28]. They observed the cauliflower or ball-shaped diamond formation, so-called 


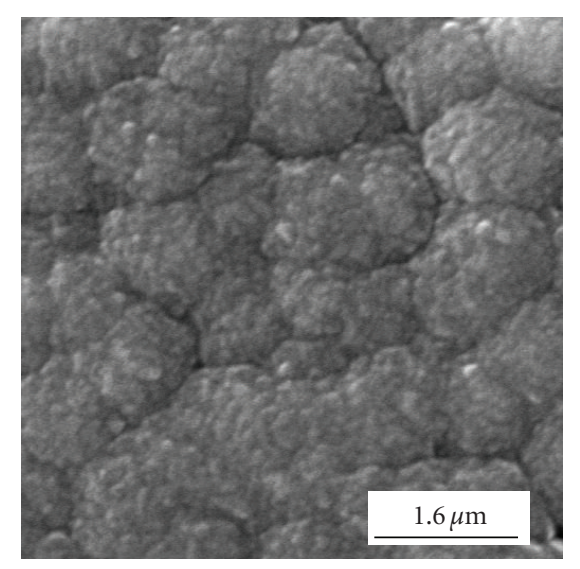

FIGURE 8: SEM image of BDND film grown on a silicon substrate.

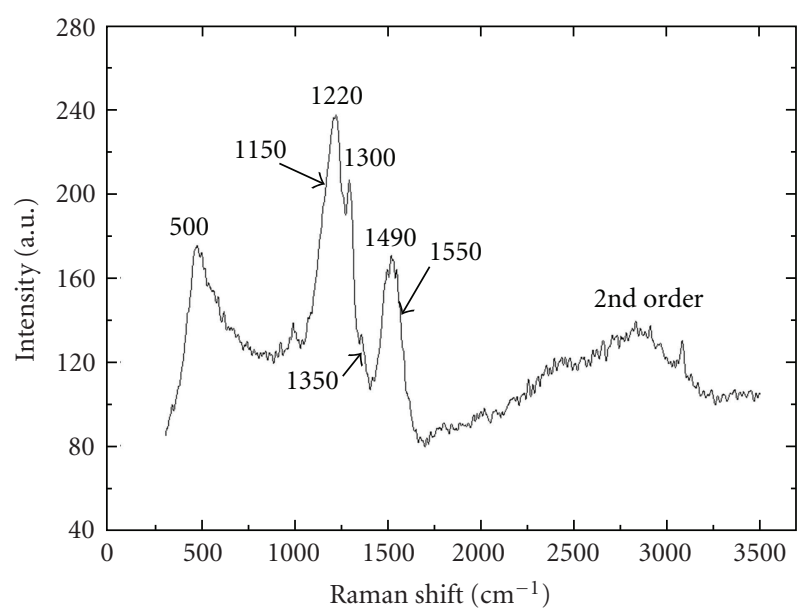

FIGURE 9: Raman spectrum of BDND film grown on a silicon substrate.

CVD ballas diamond, when argon concentrations above $30 \%$ were used. They discussed that ballas diamond is nearly pure diamond with strongly twinned microstructure and grows at the transition from faceted diamond to graphite depositions. This film was prepared by HFCVD technique using the following growth parameters: temperature of the $900 \mathrm{~K}$, pressure of the $6.7 \mathrm{KPa}$, deposition time of the $6 \mathrm{~h}$, and gas mixture of $\mathrm{CH}_{4} / \mathrm{H}_{2} / \mathrm{Ar}$ with a flow of $1 / 19 / 80 \mathrm{sccm}$.

Boron doping was obtained by forcing $\mathrm{H}_{2}$ through a bubbler with $\mathrm{B}_{2} \mathrm{O}_{3}$ dissolved in methanol. The doping level corresponds to the acceptor concentrations at about $10^{20} \mathrm{~cm}^{-3}$ atoms B/C, calculated from Mott-Schottky plot analysis. The presence of boron incorporation in the film can be observed from Raman spectrum shown in Figure 9. The spectrum covered a range from 300 to $3500 \mathrm{~cm}^{-1}$.

Eight features were identified in the Raman spectrum of BDND film. The diamond peak is visible, and shifted to lower wavenumber $\left(1300 \mathrm{~cm}^{-1}\right)$ that is related to impurities formed in heavily doped films showing a metallic conductivity [96]. The bands at 1350 and $1550 \mathrm{~cm}^{-1}$ correspond to the $\mathrm{D}$ and $\mathrm{G}$ band, respectively. Besides, the spectrum exhibited a shoulder at $1150 \mathrm{~cm}^{-1}$ and a peak at $1490 \mathrm{~cm}^{-1}$

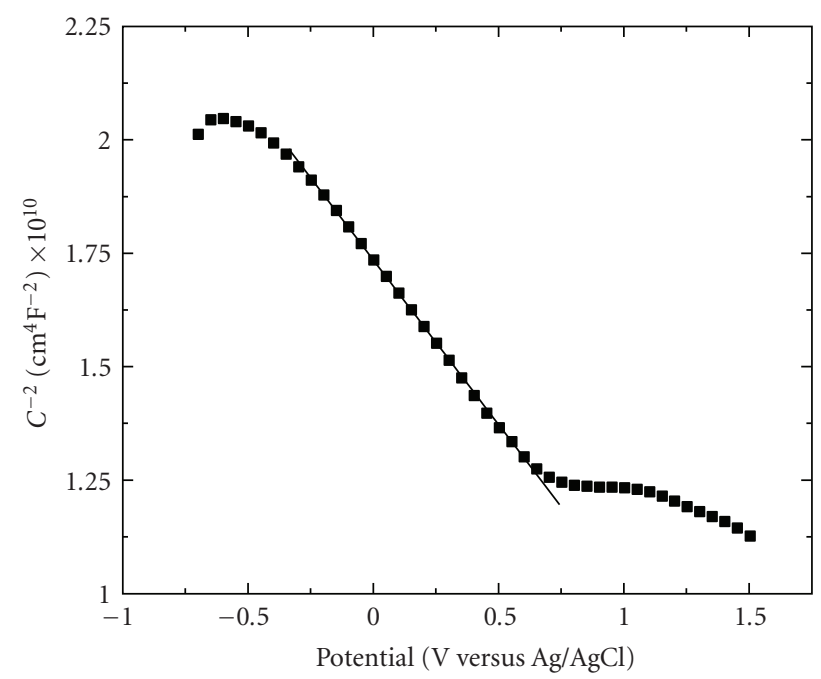

Figure 10: Room temperature Mott-Schottky plot $\mathrm{C}^{-2}$ versus the potential in $0.5 \mathrm{~mol} \mathrm{~L}^{-1} \mathrm{H}_{2} \mathrm{SO}_{4}$ obtained at $1000 \mathrm{~Hz}$ for as-grown BDND film.

related to TPA at the grain boundaries of NCD surface. The broad bands at about 500 and $1220 \mathrm{~cm}^{-1}$ present in these films are still subject to an intense debate. They have been associated with the actual boron incorporation in the lattice, rather than the hole concentration [97]. The presence of the $500 \mathrm{~cm}^{-1}$ peak is attributed to the concentration increase of the boron pairs. These boron pairs have local vibration modes giving wide bands at about of $500 \mathrm{~cm}^{-1}$ [97]. In addition, the band centered at $1220 \mathrm{~cm}^{-1}$ is attributed to the Fano interference between the discrete phonon state and the electronic continuum. Pruvost and Deneuville [98] have suggested that the Fano effect appears above a critical percolation threshold for the achievement of the metallic conductivity on the boron impurity band. Meanwhile, Ager et al. [99] have reported that the Fano effect is attributed to the transition from the broadened impurity band to continuum states composed of the excited acceptor and valence band sates.

In the following, the graph of Figure 10 represents the Mott-Schottky plot of as-grown BDND electrode. The physical meaning of a Mott-Schottky plot is related to the effect of potential $E$ on the thickness of the space-charge layer in the semiconductor. The intercept of the linear part of the curve with the potential axis at $\mathrm{C}^{-2}=0$ represents the flatband potential $\left(E_{\mathrm{FB}}\right)$, while the slope of the curve allows to determine the acceptor densities in the semiconductor [100]. The value of $E_{\mathrm{FB}}$ was about $+2.4 \mathrm{~V}$ versus $\mathrm{Ag} / \mathrm{AgCl}$.

Several works describe the use of electrochemical impedance spectroscopy as well as the capacitance-potential measurements to demonstrate the differences in electrode behavior after cathodic or anodic pretreatment of the BDD films [101-103]. For example, Actis et al. [101] have mentioned that the values of the flat band potentials for $\mathrm{H}$-terminated BDD and for photochemically oxidized BDD were $0.52 \mathrm{~V}$ and $1.11 \mathrm{~V}$ versus SCE, respectively. Becker and Jüttner [104] have explained the occurrence of the 
resistance associated to the high-frequency element in the BDD impedance by a partial blocking of the diamond electrode surface. However, this resistance is reduced when the BDD surface undergoes the cathodic treatment. This could be related to a superficial conductive layer (SCL) that exists on hydrogen-terminated diamond surface and it can improve the charge transfer and may explain the enhanced electrochemical response [103]. Furthermore, according to Girard et al. [105], a notable positive shift for $E_{\mathrm{FB}}$ in the BDD as-gown electrode from 1.0 to $3.0 \mathrm{~V}$ versus $\mathrm{Hg} / \mathrm{Hg}_{2} \mathrm{SO}_{4}$ was observed after the anodic process that contributed to the increase of oxygen terminations. This is also supported by Simon et al. [106] that have reported a positive shift in $E_{\mathrm{FB}}$ as characteristic for the formation of $\mathrm{C}-\mathrm{O}$ structures. Considering the fact that the source of boron doping is a solution of methanol and $\mathrm{B}_{2} \mathrm{O}_{3}$, it is expected that there was the presence of oxygen-terminated on the surface of this film.

In relation to the electrochemical characteristics of this BDND electrode, its properties are very close to be observed by other authors. $\mathrm{CV} i-E$ curve for this film in $0.5 \mathrm{~mol} \mathrm{~L}^{-1}$ $\mathrm{H}_{2} \mathrm{SO}_{4}\left(0.1 \mathrm{~V} \cdot \mathrm{s}^{-1}\right)$ and the curve obtained in $1 \mathrm{mM}$ of $\mathrm{Fe}(\mathrm{CN})_{6}{ }^{-3 /-4}+0.5 \mathrm{~mol} \mathrm{~L}^{-1} \mathrm{H}_{2} \mathrm{SO}_{4}\left(0.1 \mathrm{~V} \cdot \mathrm{s}^{-1}\right)$ as shown in Figure 11.

Electrochemistry response for the BDND film showed a low capacitance and stable background current, around $3 \mu \mathrm{A} \mathrm{cm}^{-2}$ at $500 \mathrm{mV}$. The working potential window for this film is approximately $2.3 \mathrm{~V}$ versus $\mathrm{Ag} / \mathrm{AgCl}$ where the oxidation water begins at $1.8 \mathrm{~V}$ and the reduction water begins at $-0.5 \mathrm{~V}$. This value is approximately the same as observed by Siew et al. [15], ca. $2.6 \mathrm{~V}$ versus $\mathrm{Ag} / \mathrm{AgCl}$, and Zhao et al. [107], ca. $2.8 \mathrm{~V}$ versus SCE, but, slightly lower than the values obtained by Hupert et al. [7], Wang et al. [11], and Show et al. [72], ca. 3.0 V versus Ag/AgCl. Regardless of differences between the values of working potential window, the value of the peak potential separation $\left(\Delta E_{p}\right)$ observed for all the films $[7,13,107]$ was very similar to ours results, approximately $80 \mathrm{mV}$. Remembering that a lower $\Delta E_{p}$ $(\sim 59 \mathrm{mV})$ reflects the rapid reaction kinetics at the electrode surface and is compatible with the activity of the same.

\subsubsection{Applications of Boron-Doped Nanocrystalline Dia-} mond Electrodes. Boron-doped nanocrystalline diamond electrodes can be used for a multitude of applications because of their unique electrochemical properties that largely differ from that of conventional electrode materials. The electrochemical process of these electrodes permit to obtain results that was not possible with conventional electrodes. Some of the results are related to organic substances which have been determined so far with BDND electrodes, such as aminobiphenyls [108], ganciclovir [109], oxalic acid [110], DNA [111], glucose [107, 112, 113], protein [114], and dopamine [15].

The determination of heavy metal ultratraces is a tough challenge for analysts. Human activity, principally during the last two centuries, has released these toxic metals into the environment and now the impact on the health of humans, animals, and plants is obvious. Spectroscopic and electroanalytical techniques have been widely used, but the principal difference between them is related to the
TABLE 2: Quantification limit ( $\mathrm{ppb}$ ) of different heavy metals for BDND electrodes using ASV.

\begin{tabular}{lccc}
\hline Metals & Ref. [72] & Ref. [115] & Ref. [117] \\
\hline $\mathrm{Ag}(\mathrm{I})$ & 0.11 & - & 1.0 \\
$\mathrm{Cu}(\mathrm{II})$ & 0.64 & 3.0 & 10.0 \\
$\mathrm{~Pb}(\mathrm{II})$ & 2.07 & 3.8 & 5.0 \\
$\mathrm{Cd}(\mathrm{II})$ & 1.12 & 1.2 & 1.0 \\
$\mathrm{Zn}(\mathrm{II})$ & 6.54 & 5.0 & 50.0 \\
\hline
\end{tabular}

instrumental cost. Electroanalytical techniques are simple to use in situ and the apparatus is easy to handle for measurements in rivers or lakes.

In the recent past and nowadays, inductively coupled plasma atomic emission spectroscopy (ICP-AES), inductively coupled plasma mass spectroscopy (ICP-MS), and related techniques have been widely used to determine low levels of heavy metals in pharmaceutical drugs, food and fish, wine, highly concentrated salt water, or marine microalgae Fucus [115]. However, electroanalytical techniques may compete with spectral methods for selected heavy metals such as copper, lead, cadmium, and zinc because these four metals are known as reversible (rapid electron exchange) and their signals are wide even at low concentration $[72,115$, 116]. Using anodic stripping voltammetry (ASV), Tall et al. [115] and Show et al. [72] were able to detect and quantify $\mathrm{Ag}(\mathrm{I}), \mathrm{Cu}(\mathrm{II}), \mathrm{Pb}(\mathrm{II}), \mathrm{Cd}(\mathrm{II})$, and $\mathrm{Zn}(\mathrm{II})$ as shown in Table 2. The difference of values presented in Table 2 is related to the experimental conditions used by each author. The results using BDD obtained by McGaw and Swain. [117] were also included in Table 2 to show the advantages of BDND to detect these metals.

Both authors [72, 115] concluded that for the metals studied, the BDND electrode provides good sensitivity, low limits of detection, valuable response precision, and superb response stability for several contaminated samples, such as lake and well water, tap water, wastewater treatment sludge, and contaminated soil.

Some BDND electrodes have been modified superficially with the purpose to absorb a specific substance on their surfaces. The modifying agents of surface can promote selective recognition due to charge transfer, adsorption and ion exchange, or specific biological interactions. Yang et al. [118] have shown the possibility to use a surface electrochemical reaction to achieve electrically addressable biomolecular functionalization of BDND films. They provided a pathway for arrays fabrication of distinct biomolecular recognition elements on diamond surfaces, without the use of microfluidics or spotting methods. The electrically addressable functionalization started with BDND films, followed by functionalization of the diamond with nitro groups. The key to achieve electrically addressable biomolecular functionalization lies in the ability to reduce nitro groups selectively on specific electrodes to primary amines, followed by reaction with bifunctional linkers that will selectively react with the amines and covalently link them to DNA or other biomolecules of interest. 


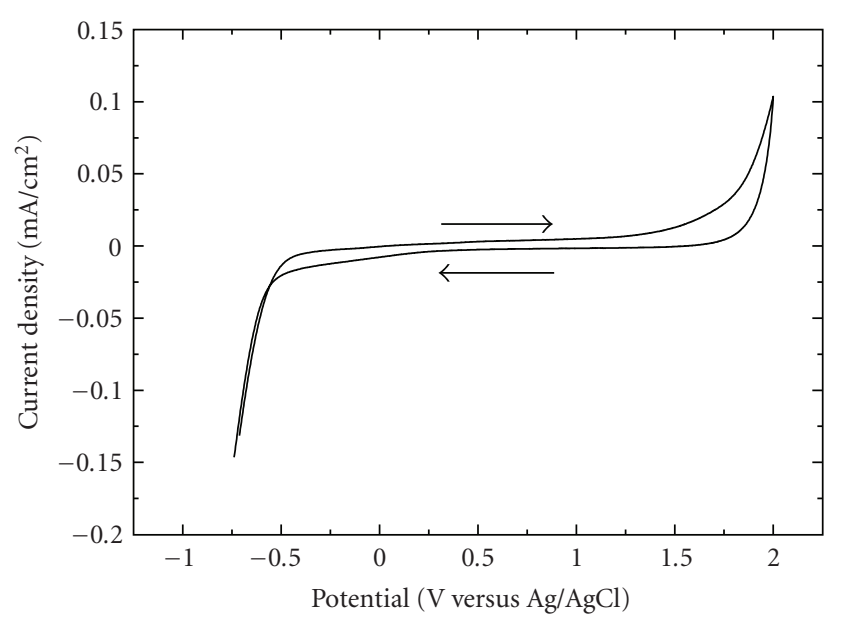

(a)

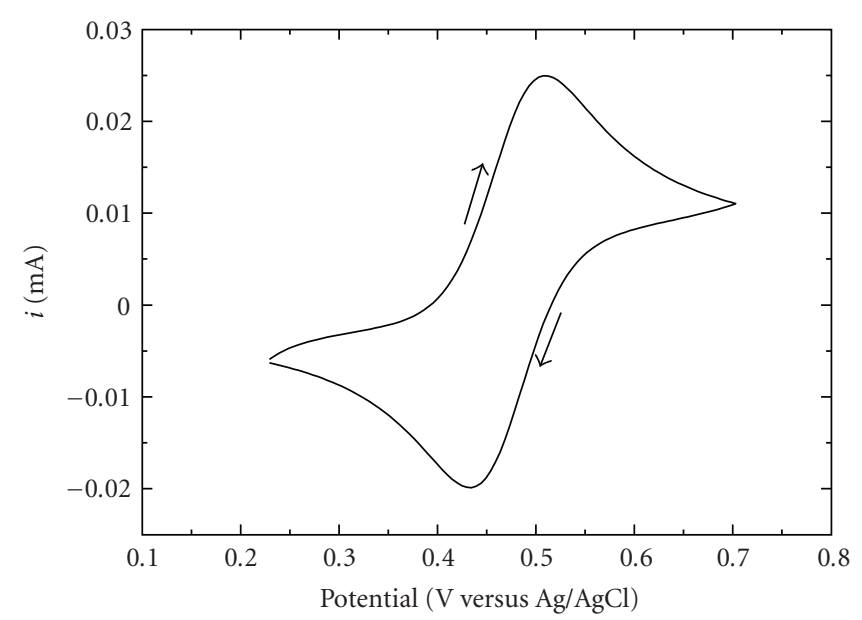

(b)

FIgure 11: CV i-E curve in (a) $0.5 \mathrm{~mol} \mathrm{~L}^{-1} \mathrm{H}_{2} \mathrm{SO}_{4}$ and (b) $1 \mathrm{~m} \mathrm{~mol} \mathrm{~L}^{-1}$ ferrocyanide $+0.5 \mathrm{~mol} \mathrm{~L}^{-1} \mathrm{H}_{2} \mathrm{SO}_{4}$ for BDND electrode. $\left(\nu=0.1 \mathrm{~V} \mathrm{~s}{ }^{-1}\right)$.

Zhou et al. [13] have also got some interesting results from the use of photochemical functionalization on BDND electrodes. They used a photochemical reaction scheme to modify hydrogen-terminated BDND surfaces chemically using a vinyl group of undecylenic acid methyl esters, followed by hydrolyzation of the esters under basic conditions to produce a monolayer of carboxylic groups on the surfaces. Cyt $c$ was covalently immobilized on the resulting carboxylterminated BDND electrode through carbodiimide coupling reaction. For comparison, they prepared counterpart biosensors in which Cyt $c$ was immobilized on BDD and glassy carbon (GC) electrodes prepared by the same procedure. The reproducibility and stability of the Cyt $c$-modified BDND electrode were investigated by the measurement of the response to $100 \mu \mathrm{M} \mathrm{H}_{2} \mathrm{O}_{2}$ in $0.1 \mathrm{M} \mathrm{PBS}$ ( $\mathrm{pH}$ 7.0). The relative standard deviation (RSD) is $2.1 \%$ for 10 successive assays. The long-term stability of the developed enzyme electrode was determined every 3 days, and $85 \%$ of its initial activity can be obtained after 6 weeks, while the Cyt $c$-modified BDD and GC electrodes retained $80 \%$ and $25 \%$ of their initial activity after 6 weeks. This result suggests that the stability of Cyt $c$-modified BDND electrode is nearly equivalent to that of the Cyt $c$-modified BDD electrode, but is significantly higher than that of the Cyt $c$-modified GC electrode. The superior stability of the Cyt $c$-modified BDND electrode may be the result of the biocompatible microenvironment for the enzyme provided by the doped diamond electrodes and the high chemical and electrochemical stability of them. Furthermore, the direct electron transfer between Cyt cmodified and the electrodes was obtained and the electron transfer is faster on the BDND than BDD because of the incorporated $\mathrm{sp}^{2}$ state carbon as charge transfer mediators on BDND surface. So, they concluded that these results make the BDND thin film an interesting candidate for the study of the direct electrochemistry of redox proteins and their sensing applications.

Currently, the water treatment is the application that most has been investigated with diamond electrode. The high overvoltage for oxygen evolution and the possibility to produce anodically hydroxyl radicals with high current efficiency makes the diamond electrodes especially interesting for destruction/detection of organic pollutants in water. The aromatic compounds, and particularly the phenolics, have high toxicity and low water solubility and are released in the wastewaters from a considerable number of industries $[119,120]$. The phenol is potentially fatal if ingested, inhaled, and absorbed by skin and may cause severe burns and affect central nervous system, liver, and kidney [120]. Although effective, existing treatments require the addition of large quantities of reagents (chemical oxidation) or considerable physical areas, long retention time, and difficult process control (biological degradation). The ease of phenol electrochemical oxidation on different electrodes prompted the use of electrochemical methods for the determination of this compound [120]. However, sensitive and stable electrochemical detection of phenols is generally impossible with most materials used for manufacturing the electrode because of irreversible adsorption of reactive intermediates that form a passive film on the electrode surface [120]. The BDND electrode described in Figure 8 (obtained in Diamond Laboratory of LAS/INPE) was used to analyze the detection of different phenolic compounds.

In Figure 12 are shown three $\mathrm{CV}$ of $1 \mathrm{mmol} \mathrm{L}^{-1}$ of 4-chlorophenol, 4-nitrophenol, and phenol in $0.5 \mathrm{~mol} \mathrm{~L}^{-1}$ $\mathrm{H}_{2} \mathrm{SO}_{4}\left(\nu=0.1 \mathrm{mV} \mathrm{s}^{-1}\right)$. After each subsequent measurement, the BDND surfaces were treated by anodic polarization $(2.8 \mathrm{~V}$ versus $\mathrm{Ag} / \mathrm{AgCl})$ for $10 \mathrm{~s}$ followed by cathodic polarization $(-2.8 \mathrm{~V}$ versus $\mathrm{Ag} / \mathrm{AgCl})$ for $10 \mathrm{~s}$. This procedure was necessary to restore the initial electrode activity $[121,122]$. The electrode presented a well-defined current profile for each phenol compound and the electrode efficiency was maintained even after several measurements. The oxidation peak potential at $1.16 \mathrm{~V}, 1.22 \mathrm{~V}$, and $1.52 \mathrm{~V}$ versus $\mathrm{Ag} / \mathrm{AgCl}$ corresponds to 4-chlorophenol, phenol, and 4-nitrophenol, respectively. 


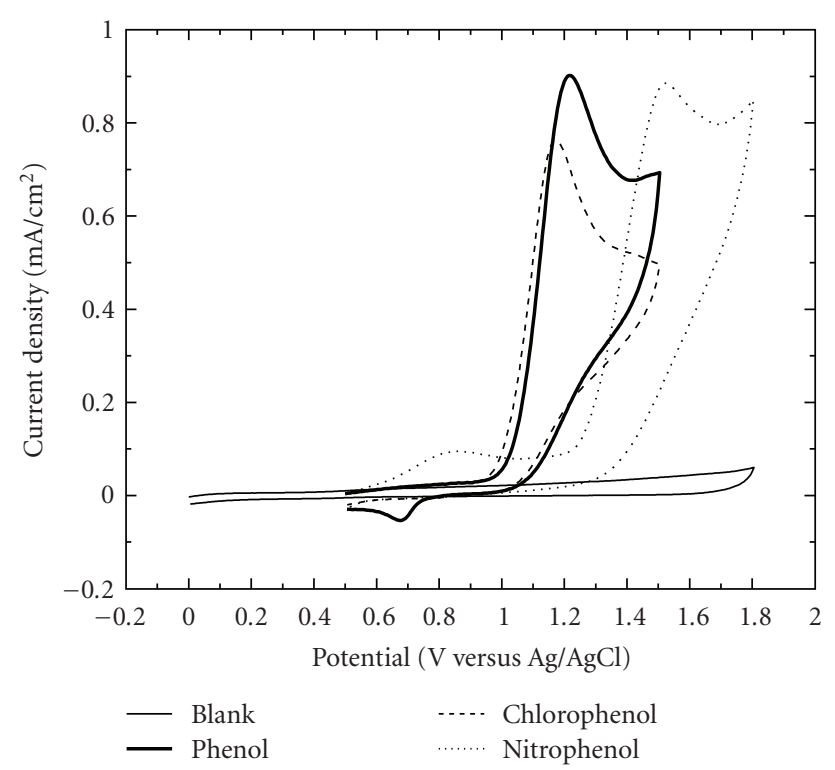

Figure 12: CV $i-E$ curve of $1 \mathrm{mmol} \mathrm{L}^{-1}$ of 4-chlorophenol, 4nitrophenol and phenol in $0.5 \mathrm{~mol} \mathrm{~L}^{-1} \mathrm{H}_{2} \mathrm{SO}_{4}$ for BDND electrode $\left(\nu=0.1 \mathrm{~V} \mathrm{~s}^{-1}\right)$.

For any quantitative method there is a range of analyte concentrations on which the method can be applied. In the low concentration range, the limiting factors are the values of detection and quantification limits [123]. The detection limit of phenol was investigated by square wave voltammetry (SWV) [124]. In this technique, the net current $\left(i_{\text {net }}\right)$, centered on the redox potential, is obtained by taking the difference between the forward and reverse currents $\left(i_{\text {for }}\right.$ $-i_{\text {rev }}$ ). The current peak height is directly proportional to electroactive species concentration and the direct determination of the detection limit is possible. Figure 13 shows the square wave voltammogram for BDND electrode. The BDND electrode presented a well-defined current profile as a function of the phenol concentration and an excellent accuracy of phenol oxidation peak at $1.12 \mathrm{~V}$ versus $\mathrm{Ag} / \mathrm{AgCl}$. In Figure 13, the inset corresponds to the analytical curve in the current peak versus the concentration in the range of 30 to $130 \mu \mathrm{mol} \mathrm{L}^{-1}$ for each electrode. From linear regression analysis of an analytical curve was found this equation:

$$
\begin{aligned}
i_{p}= & \left(-2.5057 \times 10^{-7} \pm 1.1783 \times 10^{-7}\right) \\
& +\left(1.3522 \times 10^{-7} \pm 1.1716 \times 10^{-9}\right) \\
& \times[\text { phenol }] .
\end{aligned}
$$

This equation was used to evaluate the detection limit (DL) and quantification limit (QL). The DL and QL were calculated from the criterion $\mathrm{DL}=3 \sigma / \theta$ and $\mathrm{QL}=$ $10 \sigma / \theta$, respectively, where $\sigma$ denotes the standard deviation of arithmetic media of the currents obtained from ten voltammograms of blanks and $\theta$ is the slope of analytical curves [124]. The BDND electrode presented a phenol DL of $0.1 \mathrm{mg} \mathrm{L}^{-1}$ and phenol QL of $0.4 \mathrm{mg} \mathrm{L}^{-1}$.

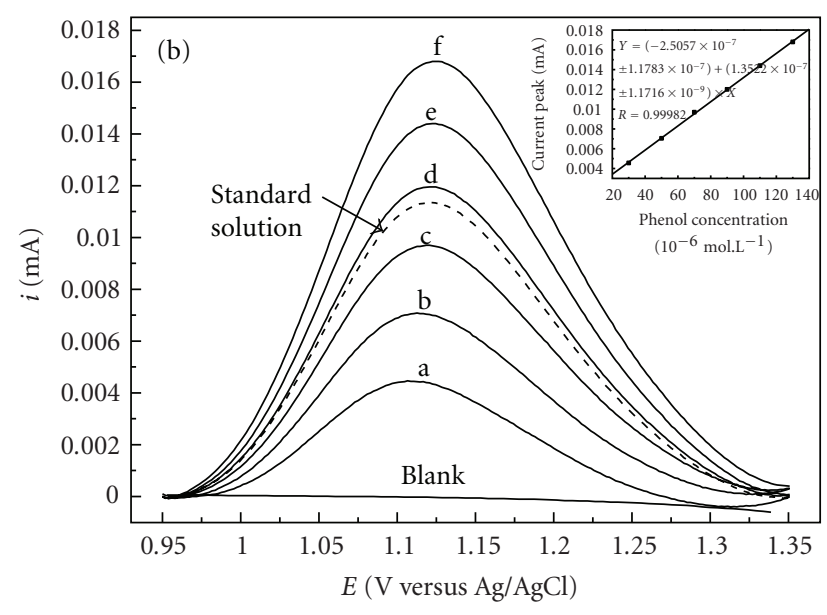

FIGURE 13: Square wave voltammogram in $0.5 \mathrm{~mol} \mathrm{~L}^{-1} \mathrm{H}_{2} \mathrm{SO}_{4}$ for different phenol concentrations from (a) 30; (b) 50; (c) 70; (dash style) standard solution; (d) 90; (e) 110 and (f) $130 \mu \mathrm{mol} \mathrm{L}{ }^{-1}$, using BDND electrode. $\mathrm{f}=60 \mathrm{~Hz}$, step potential $=2 \mathrm{mV}$ and amplitude $=$ $70 \mathrm{mV}$. Inset: analytical curve for phenol peak.

In Figure 13 also appears a voltammogram identified as "standard solution", but it was not considered in the previous analytical curve. This solution of $8 \mathrm{mg} \mathrm{L}^{-1}$ was prepared from a phenol standard solution of SPECSOL (SRM $136 \mathrm{f}$ NIST-USA) to validate the results obtained from the BDND electrode using SWV and chromatographic techniques. The chromatography analyses were performed using Ion Chromatograph (850 Professional IC, Metrohm) equipped with an amperometric detector (791 VA) and a phenol column (Protonsil Enviro PHE $3 \mu \mathrm{m}$ ). The eluent used for this analysis was $20 \mathrm{mmol} \mathrm{L}^{-1} \mathrm{KNO}_{3}+0.5 \mathrm{mmol} \mathrm{L}^{-1}$ $\mathrm{H}_{2} \mathrm{SO}_{4}+30 \%$ methanol + ultrapure deionized water.

The values presented below were obtained from the average of three measurements. From the equations it was possible to determine the values of phenol standard sample measured using the BDND electrode. The value was 8.2 $\pm 0.2 \mathrm{mg} \mathrm{L}^{-1}$. The same standard solution sample was also injected in the Ion Chromatograph and the value obtained was $7.9 \pm 0.1 \mathrm{mg} \mathrm{L}^{-1}$. As preliminary tests, the results showed that the methodology using the BDND electrode and SWV was very efficient.

Muna et al. [119] have also studied the efficiency of BDND electrode using other analytical techniques. They showed the results of amperometric detection of phenol coupled with Flow Injection Analysis (FIA) and High Performance Liquid Chromatography (HPLC). The values of QL presented were $0.3 \mathrm{mg} \mathrm{L}^{-1}$ and $0.1 \mathrm{mg} \mathrm{L}^{-1}$ using the FIA and HPLC, respectively. In addition, they mentioned that the QL for the phenolic analytes in their HPLC-EC method is comparable to those reported for Environmental Protection Agency (EPA) methods 1625. So, they confirmed a new possibility for use of this electrode. 


\section{Conclusions and Outlook}

The nanotechnology seeks to study the properties of nanoscale objects and their use in developing devices with these dimensions. This study includes a search by a decrease in materials, targeting a space-saving and energy, and an exploration of new effects that occur at the nanometer scale. Its applications represent a new challenge that includes the fields of physics, chemistry, biology, engineering, and pharmacy, and due to its recent development the nanotechnology has enormous potential to impact science and economics.

Conducting nanodiamond with exceptional hardness, inertness, and stability has been proven as a versatile electrode material for a wide variety of applications. There are several commercial sources that market conducting diamond thin-film electrodes with affordable cost. Undoped or doped nanodiamond electrodes can function in aggressive solution environments without any microstructural or morphological degradation. With favorable mass transport, nanoscale devices enable the study of very fast electrode kinetics and enhance the response of many electroanalytical sensors. Apparently, the undoped nanodiamond occupies a special place as an electrode material in biosensing applications, while the BDND can be considered as one of the most ideal electrode materials for electroanalysis of many chemistry compounds.

\section{Acknowledgments}

The authors are very grateful to FAPESP, CNPq, and CAPES for financial support, and Mrs. Maria Lúcia Brison de Mattos (LAS/INPE), Mr. Peter Hammer (UNESP/Araraquara) and UFSCar for SEM, XPS, and FEG-SEM analyses.

\section{References}

[1] J. E. Butler and A. V. Sumant, "The CVD of nanodiamond materials," Chemical Vapor Deposition, vol. 14, no. 7-8, pp. 145-160, 2008.

[2] T. P. Ong, W. A. Chiou, F. R. Chen, and R. P. H. Chang, "Preparation of nanocrystalline diamond films for optical coating applications using a pulsed microwave plasma CVD method," Carbon, vol. 28, no. 6, p. 799, 1990.

[3] D. M. Gruen, X. Z. Pan, A. R. Krauss, S. Z. Liu, J. S. Luo, and C. M. Foster, "Deposition and characterization of nanocrystalline diamond films," Journal of Vacuum Science \& Technology A, vol. 12, no. 4, pp. 1491-1495, 1994.

[4] D. M. Gruen, S. Liu, A. R. Krauss, J. Luo, and X. Pan, "Fullerenes as precursors for diamond film growth without hydrogen or oxygen additions," Applied Physics Letters, vol. 64, no. 12, pp. 1502-1504, 1994.

[5] D. M. Gruen, S. Liu, A. R. Krauss, and X. Pan, "Buckyball microwave plasmas: fragmentation and diamond-film growth," Journal of Applied Physics, vol. 75, no. 3, pp. 17581763, 1994.

[6] A. Gruen, "Nanocrystalline diamond films," Journal of Psychohistory, vol. 29, pp. 211-259, 1999.

[7] M. Hupert, A. Muck, J. Wang et al., "Conductive diamond thin-films in electrochemistry," Diamond and Related Materials, vol. 12, no. 10-11, pp. 1940-1949, 2003.
[8] A. Kraft, "Doped diamond: a compact review on a new, versatile electrode material," International Journal of Electrochemcal Science, vol. 2, pp. 355-385, 2007.

[9] J. H. T. Luong, K. B. Male, and J. D. Glennon, "Boron-doped diamond electrode: synthesis, characterization, functionalization and analytical applications," Analyst, vol. 134, no. 10, pp. 1965-1979, 2009.

[10] D. Zhou, D. M. Gruen, L. C. Qin, T. G. McCauley, and A. R. Krauss, "Control of diamond film microstructure by Ar additions to $\mathrm{CH}_{4} / \mathrm{H}_{2}$ microwave plasmas," Journal of Applied Physics, vol. 84, no. 4, pp. 1981-1989, 1998.

[11] S. Wang, V. M. Swope, J. E. Butler, T. Feygelson, and G. M. Swain, "The structural and electrochemical properties of boron-doped nanocrystalline diamond thin-film electrodes grown from Ar-rich and H2-rich source gases," Diamond and Related Materials, vol. 18, no. 4, pp. 669-677, 2009.

[12] B. Fausett, M. C. Granger, M. L. Hupert, J. Wang, G. M. Swain, and D. M. Gruen, "The electrochemical properties of nanocrystalline diamond thin-films deposited from C60/argon and methane/nitrogen gas mixtures," Electroanalysis, vol. 12, no. 1, pp. 7-15, 2000.

[13] Y. Zhou, J. Zhi, Y. Zou, W. Zhang, and S. T. Lee, "Direct electrochemistry and electrocatalytic activity of cytochrome $c$ covalently immobilized on a boron-doped nanocrystalline diamond electrode," Analytical Chemistry, vol. 80, no. 11, pp. 4141-4146, 2008.

[14] A. E. Fischer, Y. Show, and G. M. Swain, "Electrochemical performance of diamond thin-film electrodes from different commercial sources," Analytical Chemistry, vol. 76, no. 9, pp. 2553-2560, 2004.

[15] P. S. Siew, K. P. Loh, W. C. Poh, and H. Zhang, "Biosensing properties of nanocrystalline diamond film grown on polycrystalline diamond electrodes," Diamond and Related Materials, vol. 14, no. 3-7, pp. 426-431, 2005.

[16] W. Kulisch, C. Popov, V. Vorlicek, P. N. Gibson, and G. Favaro, "Nanocrystalline diamond growth on different substrates," Thin Solid Films, vol. 515, no. 3, pp. 1005-1010, 2006.

[17] M. Amaral, F. J. Oliveira, M. Belmonte, A. J. S. Fernandes, F. M. Costa, and R. F. Silva, "Hot-filament chemical vapour deposition of nanodiamond on silicon nitride substrates," Diamond and Related Materials, vol. 13, no. 4-8, pp. 643-647, 2004.

[18] M. R. Baldan, S. C. Ramos, E. C. Almeida, A. F. Azevedo, and N. G. Ferreira, "Homogeneous micro and nanocrystalline diamond coating on reticulated vitreous carbon treated at different temperatures," Diamond and Related Materials, vol. 17, no. 7-10, pp. 1110-1115, 2008.

[19] C. R. B. Miranda, N. A. Braga, M. R. Baldan, A. F. Beloto, and N. G. Ferreira, "Improvements in CVD/CVI processes for optimizing nanocrystalline diamond growth into porous silicon," Diamond and Related Materials, vol. 19, no. 7-9, pp. 760-763, 2010.

[20] G. Cicala, P. Bruno, F. Bénédic, F. Silva, K. Hassouni, and G. S. Senesi, "Nucleation, growth and characterization of nanocrystalline diamond films," Diamond and Related Materials, vol. 14, no. 3-7, pp. 421-425, 2005.

[21] F. Silva, F. Bénédic, P. Bruno, and A. Gicquel, "Formation of $\langle 110\rangle$ texture during nanocrystalline diamond growth: an Xray diffraction study," Diamond and Related Materials, vol. 14, no. 3-7, pp. 398-403, 2005. 
[22] Sh. Michaelson, A. Stacey, J. Orwa et al., "Bulk and surface thermal stability of ultra nanocrystalline diamond films with 10-30 nm grain size prepared by chemical vapor deposition," Journal of Applied Physics, vol. 107, pp. 093521-1-093521-7, 2010.

[23] W. S. Huang, D. T. Tran, J. Asmussen, T. A. Grotjohn, and D. Reinhard, "Synthesis of thick, uniform, smooth ultrananocrystalline diamond films by microwave plasmaassisted chemical vapor deposition," Diamond and Related Materials, vol. 15, no. 2-3, pp. 341-344, 2006.

[24] H. Kozak, A. Kromka, E. Ukraintsev et al., "Detecting sp ${ }^{2}$ phase on diamond surfaces by atomic force microscopy phase imaging and its effects on surface conductivity," Diamond and Related Materials, vol. 18, no. 5-8, pp. 722-725, 2009.

[25] A. F. Azevedo, E. J. Corat, N. F. Leite, and V. J. Trava-Airoldi, "Chemical vapor deposition diamond thin films growth on Ti6AL4V using the Surfatron system," Diamond and Related Materials, vol. 11, no. 3-6, pp. 550-554, 2002.

[26] A. F. Azevedo, E. J. Corat, N. F. Leite, N.G. Ferreira, and V. J. Trava-Airoldi, "Raman analyses of residual stress in diamond thin films grown on Ti6Al4V alloy," Materials Research, vol. 6, no. 1, pp. 51-56, 2003.

[27] S. G. Wang, Q. Zhang, S. F. Yoon et al., "Electron field emission properties of nano-, submicro- and micro-diamond films," Physica Status Solidi A, vol. 193, no. 3, pp. 546-551, 2002.

[28] T. S. Yang, J. Y. Lai, C. L. Cheng, and M. S. Wong, "Growth of faceted, ballas-like and nanocrystalline diamond films deposited in $\mathrm{CH}_{4} / \mathrm{H}_{2} / \mathrm{Ar}$ MPCVD," Diamond and Related Materials, vol. 10, no. 12, pp. 2161-2166, 2001.

[29] J. A. Carlisle and O. Auciello, "Ultrananocrystalline diamond: properties and applications in biomedical devices," Electrochemical Society Interface, vol. 12, no. 1, pp. 28-31, 2003.

[30] P. W. May and Y. A. Mankelevich, "Experiment and modeling of the deposition of ultrananocrystalline diamond films using hot filament chemical vapor deposition and $\mathrm{Ar} / \mathrm{CH}_{4} / \mathrm{H}_{2}$ gas mixtures: a generalized mechanism for ultrananocrystalline diamond growth," Journal of Applied Physics, vol. 100, no. 2, Article ID 024301, 9 pages, 2006.

[31] P. W. May, J. A. Smith, and Y. A. Mankelevich, "Deposition of NCD films using hot filament CVD and $\mathrm{Ar} / \mathrm{CH}_{4} / \mathrm{H}_{2}$ gas mixtures," Diamond and Related Materials, vol. 15, no. 2-3, pp. 345-352, 2006.

[32] J. G. Buijnsters, L. Vázquez, G. W. G. Van Dreumel, J. J. Ter Meulen, W. J. P. Van Enckevort, and J. P. Celis, "Enhancement of the nucleation of smooth and dense nanocrystalline diamond films by using molybdenum seed layers," Journal of Applied Physics, vol. 108, no. 10, Article ID 103514, 9 pages, 2010.

[33] G. F. Zhang and V. Buck, "Lower filament temperature limit of diamond growth in a hot-filament CVD system," Surface and Coatings Technology, vol. 160, no. 1, pp. 14-19, 2002.

[34] K. K. Hirakuri, T. Kobayashi, E. Nakamura, N. Mutsukura, G. Friedbacher, and Y. Machi, "Influence of the methane concentration on HF-CVD diamond under atmospheric pressure," Vacuum, vol. 63, no. 3, pp. 449-454, 2001.

[35] Y. H. Tang, X. T. Zhou, Y. F. Hu, C. S. Lee, S. T. Lee, and T. K. Sham, "A soft X-ray absorption study of nanodiamond films prepared by hot-filament chemical vapor deposition," Chemical Physics Letters, vol. 372, no. 3-4, pp. 320-324, 2003.

[36] N. G. Ferreira, A. F. Azevedo, A. F. Beloto et al., "Nanodiamond films growth on porous silicon substrates for electrochemical applications," Diamond and Related Materials, vol. 14, no. 3-7, pp. 441-445, 2005.
[37] S. Potocky, A. Kromka, J. Potmesil et al., "Investigation of nanocrystalline diamond films grown on silicon and glass at substrate temperature below $400{ }^{\circ} \mathrm{C}$," Diamond and Related Materials, vol. 16, no. 4-7, pp. 744-747, 2007.

[38] T. S. Yang, J. Y. Lai, M. S. Wong, and C. L. Cheng, "Substrate bias effect on the formation of nanocrystalline diamond films by microwave plasma-enhanced chemical vapor deposition," Journal of Applied Physics, vol. 92, no. 4, pp. 2133-2138, 2002.

[39] V. J. Trava-Airoldi, A. F. Azevedo, E. J. Corat, J. R. Moro, and N. F. Leite, "Diamond deposition using surface wave system with high microwave power," Brazilian Journal of Vacuum Applications, vol. 19, no. 1, pp. 6-10, 2000.

[40] A. F. Azevedo, N. G. Ferreira, E. J. Corat, and V. J. TravaAiroldi, "Adherence measurements of nanodiamond thin films grown on Ti6Al4V alloy," Journal of Metastable and Nanocrystalline Materials, vol. 20-21, pp. 753-757, 2004.

[41] K. Wu, E. G. Wang, Z. X. Cao, Z. L. Wang, and X. Jiang, "Microstructure and its effect on field electron emission of grain-size-controlled nanocrystalline diamond films," Journal of Applied Physics, vol. 88, no. 5, pp. 2967-2974, 2000.

[42] A. F. Azevedo, J. T. Matsushima, F. C. Vicentin, M. R. Baldan, and N. G. Ferreira, "Surface characterization of NCD films as a function of sp2/sp3 carbon and oxygen content," Applied Surface Science, vol. 255, no. 13-14, pp. 6565-6570, 2009.

[43] S. C. Ramos, A. F. Azevedo, M. R. Baldan, and N. G. Ferreira, "Effect of methane addition on ultrananocrystalline diamond formation: morphology changes and induced stress," Journal of Vacuum Science and Technology A, vol. 28, no. 1, pp. 27-32, 2010.

[44] A. F. Azevedo, S. C. Ramos, M. R. Baldan, and N. G. Ferreira, "Graphitization effects of $\mathrm{CH}_{4}$ addition on NCD growth by first and second Raman spectra and by X-ray diffraction measurements," Diamond and Related Materials, vol. 17, no. 7-10, pp. 1137-1142, 2008.

[45] A. F. Azevedo, V. J. Trava-Airoldi, and N. G. Ferreira, "Bias-Enhanced nucleation of NCD on high-adherent diamond/Ti6Al4V films," International Journal of Nanomanufacturing, vol. 2, no. 1-2, pp. 70-79, 2008.

[46] Y. F. Zhang, F. Zhang, Q. J. Gao, X. F. Peng, and Z. D. Lin, "The roles of argon addition in the hot filament chemical vapor deposition system," Diamond and Related Materials, vol. 10, no. 8, pp. 1523-1527, 2001.

[47] M. Vila, M. Amaral, F. J. Oliveira, R. F. Silva, A. J. S. Fernandes, and M. R. Soares, "Residual stress minimum in nanocrystalline diamond films," Applied Physics Letters, vol. 89, no. 9, Article ID 093109, 3 pages, 2006.

[48] Y. Lifshitz, C. H. Lee, Y. Wu, W. J. Zhang, I. Bello, and S. T. Lee, "Role of nucleation in nanodiamond film growth," Applied Physics Letters, vol. 88, no. 24, Article ID 243114, 3 pages, 2006.

[49] T. Soga, T. Sharda, and T. Jimbo, "Precursors for CVD growth of nanocrystalline diamond," Physics of the Solid State, vol. 46, no. 4, pp. 720-725, 2004.

[50] J. E. Butler and I. Oleynik, "A mechanism for crystal twinning in the growth of diamond by chemical vapour deposition," Philosophical Transactions of the Royal Society A, vol. 366, no. 1863, pp. 295-311, 2008.

[51] D. C. Barbosa, L. L. Melo, V. J. Trava-Airoldi, and E. J. Corat, "The activation energy for nanocrystalline diamond films deposited from an $\mathrm{Ar} / \mathrm{H} 2 / \mathrm{CH} 4$ hot-filament reactor," Journal of Nanoscience and Nanotechnology, vol. 9, no. 6, pp. 39443948, 2009. 
[52] D. C. Barbosa, P. R. P. Barreto, V. J. Trava-Airoldi, and E. J. Corat, "Growth and characterization of diamond micro and nano crystals obtained using different methane concentration in argon-rich gas mixture," Diamond and Related Materials, vol. 19, no. 7-9, pp. 768-771, 2010.

[53] W. Haenni, P. Rychen, M. Fryda, and C. Comninellis, "Semiconductors and Semimetals series," in Thin-Film Diamond B, Ch. Nebel, Ed., p. 149, Academic Press, Elsevier, 2004.

[54] Q. Liang, J. G. Harrison, and Y. K. Vohra, "Modeling of nitrogen/diborane/methane/hydrogen plasma for nanocrystalline diamond growth: comparison with experimental data," Diamond and Related Materials, vol. 17, no. 12, pp. 2067-2070, 2008.

[55] P. Hartmann, R. Haubner, and B. Lux, "Effects of simultaneous boron and nitrogen addition on hot-filament CVD diamond growth," Diamond and Related Materials, vol. 6, no. 2-4, pp. 456-462, 1997.

[56] S. Koizumi, K. Watanabe, M. Hasegawa, and H. Kanda, "Ultraviolet emission from a diamond pn junction," Science, vol. 292, no. 5523, pp. 1899-1901, 2001.

[57] S. J. Sque, R. Jones, J. P. Goss, and P. R. Briddon, "Shallow donors in diamond: chalcogens, pnictogens, and their hydrogen complexes," Physical Review Letters, vol. 92, no. 1, Article ID 017402, 4 pages, 2004.

[58] M. Iwaki, S. Sato, K. Takahashi, and H. Sakairi, "Electrical conductivity of nitrogen and argon implanted diamond," Nuclear Instruments and Methods In Physics Research, vol. 209-210, no. 2, pp. 1129-1133, 1983.

[59] Y. V. Pelskov, A. Y. Sakharova, M. D. Krotova, L. L. Bouilov, and B. V. Spitsyn, "Photoelectrochemical properties of semiconductor diamond," Journal of Electroanalytical Chemistry, vol. 228, no. 1-2, pp. 19-27, 1987.

[60] A. N. Jones, W. Ahmed, I. U. Hassan et al., "The impact of inert gases on the structure, properties and growth of nanocrystalline diamond," Journal of Physics Condensed Matter, vol. 15, no. 39, pp. S2969-S2975, 2003.

[61] M. J. Jackson, A. N. Jones, and W. Ahmed, "Experimental and gas phase modeling of nanocrystalline diamond films grown on titanium alloys for biomedical applications," Journal of Materials Engineering and Performance, vol. 14, no. 5, pp. 565-568, 2005.

[62] T. Ikeda and K. Teii, "Comparative study on nanocrystalline diamond growth from acetylene and methane," Diamond and Related Materials, vol. 15, no. 4-8, pp. 635-638, 2006.

[63] K. Brühne, K. V. Kumar, H. J. Fecht, P. Gluche, and A. Flöter, "Nanocrystalline HF-CVD-grown diamond and its industrial applications," Reviews on Advanced Materials Science, vol. 10, no. 64, pp. 224-228, 2005.

[64] J. Birrell, J. E. Gerbi, O. Auciello, J. M. Gibson, J. Johnson, and J. A. Carlisle, "Interpretation of the Raman spectra of ultrananocrystalline diamond," Diamond and Related Materials, vol. 14, no. 1, pp. 86-92, 2005.

[65] P. K. Chu and L. Li, "Characterization of amorphous and nanocrystalline carbon films," Materials Chemistry and Physics, vol. 96, no. 2-3, pp. 253-277, 2006.

[66] A. C. Ferrari and J. Robertson, "Raman spectroscopy of amorphous, nanostructured, diamond-like carbon, and nanodiamond," Philosophical Transactions of the Royal Society A, vol. 362, no. 1824, pp. 2477-2512, 2004.

[67] J. K. Shin, C. S. Lee, K. R. Lee, and K. Y. Eun, "Effect of residual stress on the Raman-spectrum analysis of tetrahedral amorphous carbon films," Applied Physics Letters, vol. 78, no. 5, pp. 631-633, 2001.
[68] S. Ferro, M. Dal Colle, and A. De Battisti, "Chemical surface characterization of electrochemically and thermally oxidized boron-doped diamond film electrodes," Carbon, vol. 43, no. 6, pp. 1191-1203, 2005.

[69] P. Chen and R. L. McCreery, "Control of electron transfer kinetics at glassy carbon electrodes by specific surface modification," Analytical Chemistry, vol. 68, no. 22, pp. 39583965, 1996.

[70] L. C. Hian, K. J. Grehan, R. G. Compton, J. S. Foord, and F. Marken, "Influence of thin film properties on the electrochemical performance of diamond electrodes," Diamond and Related Materials, vol. 12, no. 3-7, pp. 590-595, 2003.

[71] J. Foord and J. P. Hu, "Electrochemical oxidation and reduction processes at diamond electrodes of varying phase purity," Physica Status Solidi (A) Applications and Materials, vol. 203, no. 12, pp. 3121-3127, 2006.

[72] Y. Show, M. A. Witek, P. Sonthalia, and G. M. Swain, "Characterization and electrochemical responsiveness of boron-doped nanocrystalline diamond thin-film electrodes," Chemistry of Materials, vol. 15, no. 4, pp. 879-888, 2003.

[73] M. C. Granger and G. M. Swain, "The influence of surface interactions on the reversibility of ferri/ferrocyanide at boron-doped diamond thin-film electrodes," Journal of the Electrochemical Society, vol. 146, no. 12, pp. 4551-4558, 1999.

[74] D. M. Gruen, A. R. Krauss, D. Zhou et al., "Nanocrystalline diamond films from argon microwave plasmas: phase purity, microstrucuture, growth mechanism, and applications," in Electrochemical Society Proceedings, vol. PV 97-25, p. 325, Pennington, NJ, USA, 1997.

[75] V. Raiko, R. Spitzl, J. Engemann, V. Borisenko, and V. Bondarenko, "MPCVD diamond deposition on porous silicon pretreated with the bias method," Diamond and Related Materials, vol. 5, no. 10, pp. 1063-1069, 1996.

[76] A. F. Azevedo, E. J. Corat, N. G. Ferreira, and V. J. TravaAiroldi, "Wettability and corrosion tests of diamond films grown on Ti6Al4V alloy," Surface and Coatings Technology, vol. 194, no. 2-3, pp. 271-275, 2005.

[77] L. C. Hian, K. J. Grehan, C. H. Goeting, R. G. Compton, J. S. Foord, and F. Marken, "Nanodiamond thin film electrodes: metal electro-deposition and stripping processes," Electroanalysis, vol. 15, no. 3, pp. 169-174, 2003.

[78] L. C. Hian, K. J. Grehan, R. G. Compton, J. S. Foord, and F. Marken, "Nanodiamond thin films on titanium substrates growth and electrochemical properties," Journal of the Electrochemical Society, vol. 150, no. 1, pp. E59-E65, 2003.

[79] N. A. Braga, C. A. A. Cairo, J. T. Matsushima, M. R. Baldan, and N. G. Ferreira, "Diamond/porous titanium three-dimensional hybrid electrodes," Journal of Solid State Electrochemistry, vol. 14, no. 2, pp. 313-321, 2010.

[80] R. C. Mani, S. Sharma, M. K. Sunkara et al., "Synthesis and electrochemical characteristics of a nanocomposite diamond electrode," Electrochemical and Solid-State Letters, vol. 5, no. 6, pp. E32-E35, 2002.

[81] S. P. Lawrence and R. K. Don, Diamond: Electronic Properties and Applications, Kluwer Academic Publishers, Boston, Mass, USA, 1995.

[82] F. Klauser, M. Hermann, D. Steinmüller-Nethl et al., "Direct and protein-mediated cell attachment on differently terminated Nanocrystalline diamond," Chemical Vapor Deposition, vol. 16, no. 1-3, pp. 42-49, 2010.

[83] T. S. Huang, Y. Tzeng, Y. K. Liu et al., "Immobilization of antibodies and bacterial binding on nanodiamond and carbon nanotubes for biosensor applications," Diamond and Related Materials, vol. 13, no. 4-8, pp. 1098-1102, 2004. 
[84] A. Poghossian, M. H. Abouzar, A. Razavi et al., "Nanocrystalline-diamond thin films with high $\mathrm{pH}$ and penicillin sensitivity prepared on a capacitive $\mathrm{Si}-\mathrm{SiO} 2$ structure," Electrochimica Acta, vol. 54, no. 25, pp. 5981-5985, 2009.

[85] M. H. Abouzar, A. Poghossian, A. Razavi et al., "Characterisation of capacitive field-effect sensors with a nanocrystallinediamond film as transducer material for multi-parameter sensing," Biosensors and Bioelectronics, vol. 24, no. 5, pp. 1298-1304, 2009.

[86] J. Rubio-Retama, J. Hernando, B. Lopez-Ruiz et al., "Synthetic nanocrystalline diamond as a third-generation biosensor support," Langmuir, vol. 22, pp. 5837-5842, 2006.

[87] W. Yang, O. Auciello, J. E. Butler et al., "DNA-modified nanocrystalline diamond thin-films as stable, biologically active substrates," Nature Materials, vol. 1, no. 4, pp. 253-257, 2002.

[88] C. V. Guterl, E. Frackowiak, K. Jurewicz, M. Friebe, J. Parmentier, and F. Béguin, "Electrochemical energy storage in ordered porous carbon materials," Carbon, vol. 43, no. 6, pp. 1293-1302, 2005.

[89] E. Frackowiak and F. Béguin, "Carbon materials for the electrochemical storage of energy in capacitors," Carbon, vol. 39, no. 6, pp. 937-950, 2001.

[90] E. C. Almeida, A. F. Azevedo, M. R. Baldan, N. A. Braga, J. M. Rosolen, and N. G. Ferreira, "Nanocrystalline diamond/carbon felt as a novel composite for electrochemical storage energy in capacitor," Chemical Physics Letters, vol. 438, no. 1-3, pp. 47-52, 2007.

[91] J. H. Chen, W. Z. Li, D. Z. Wang, S. X. Yang, J. G. Wen, and Z. F. Ren, "Electrochemical characterization of carbon nanotubes as electrode in electrochemical doublelayer capacitors," Carbon, vol. 40, no. 8, pp. 1193-1197, 2002.

[92] M. Yoshimura, K. Honda, R. Uchikado et al., "Electrochemical characterization of nanoporous honeycomb diamond electrodes in non-aqueous electrolytes," Diamond and Related Materials, vol. 10, no. 3-7, pp. 620-626, 2001.

[93] E. L. Silva, M. A. Neto, A. J. S. Fernandes et al., "Fast coating of ultramicroelectrodes with boron-doped nanocrystalline diamond," Diamond and Related Materials, vol. 19, no. 10, pp. 1330-1335, 2010.

[94] Y. Show, V. M. Swope, and G. M. Swain, "The effect of the $\mathrm{CH} 4$ level on the morphology, microstructure, phase purity and electrochemical properties of carbon films deposited by microwave-assisted CVD from Ar-rich source gas mixtures," Diamond and Related Materials, vol. 18, no. 12, pp. 14261434, 2009.

[95] Z. Gao, V. Carabelli, E. Carbone et al., "Transparent diamond microelectrodes for biochemical application," Diamond and Related Materials, vol. 19, no. 7-9, pp. 1021-1026, 2010.

[96] C. Lévy-Clément, N. A. Ndao, A. Katty et al., "Boron doped diamond electrodes for nitrate elimination in concentrated wastewater," Diamond and Related Materials, vol. 12, no. 3-7, pp. 606-612, 2003.

[97] M. Bernard, C. Baron, and A. Deneuville, "About the origin of the low wave number structures of the Raman spectra of heavily boron doped diamond films," Diamond and Related Materials, vol. 13, no. 4-8, pp. 896-899, 2004.

[98] F. Pruvost and A. Deneuville, "Analysis of the Fano in diamond," Diamond and Related Materials, vol. 10, no. 3-7, pp. 531-535, 2001.

[99] J. W. Ager III, W. Walukiewicz, M. McCluskey, M. A. Plano, and M. I. Landstrass, "Fano interference of the Raman phonon in heavily boron-doped diamond films grown by chemical vapor deposition," Applied Physics Letters, vol. 66, pp. 616-618, 1995.

[100] Y. V. Pleskov, "Electrochemistry of diamond: a review," Russian Journal of Electrochemistry, vol. 38, pp. 1275-1291, 2002.

[101] P. Actis, A. Denoyelle, R. Boukherrroub, and S. Szunerits, "Influence of the surface termination on the electrochemical properties of boron-doped diamond (BDD) interfaces," Electrochemistry Communications, vol. 10, pp. 402-406, 2008.

[102] H. B. Suffredini, V. A. Pedrosa, L. Codognoto, S. A. S. Machado, R. C. Rocha-Filho, and L. A. Avaca, "Enhanced electrochemical response of boron-doped diamond electrodes brought on by a cathodic surface pre-treatment," Electrochimica Acta, vol. 49, no. 22-23, pp. 4021-4026, 2004.

[103] H. Girard, N. Simon, D. Ballutaud, E. Rochefoucauld, and A. Etcheberry, "Effects of controlled anodic treatments on electrochemical behavior of boron doped diamond," Diamond and Related Materials, vol. 16, pp. 888-891, 2007.

[104] D. Becker and K. Jüttner, "Impedance measurements on boron-doped diamond electrodes at different doping levels," New Diamond and Frontier Carbon Technology, vol. 13, pp. 67-78, 2003.

[105] H. Girard, N. Simon, D. Ballutaud, M. Herlem, and A. Etcheberry, "Effect of anodic and cathodic treatments on the charge transfer of boron doped diamond electrodes," Diamond and Related Materials, vol. 16, no. 2, pp. 316-325, 2007.

[106] N. Simon, H. Girard, D. Ballutaud et al., "Effect of H and $\mathrm{O}$ termination on the charge transfer of moderately boron doped diamond electrodes," Diamond and Related Materials, vol. 14, no. 3-7, pp. 1179-1182, 2005.

[107] J. Zhao, J. Wang, J. Zhi, and Z. Zhang, "Preparation of grain size controlled boron-doped diamond thin films and their applications in selective detection of glucose in basic solutions," Science China Chemistry, vol. 53, no. 6, pp. 13781384,2010

[108] J. Barek, K. Jandova, K. Peckova, and J. Zima, "Voltammetric determination of aminobiphenyls at a boron-doped nanocrystalline diamond film electrode," Talanta, vol. 74, pp. 421-426, 2007.

[109] Y. Zhou, J. Zhi, X. Zhang, and M. Xu, "Electrochemical studies of ganciclovir at boron-doped nanocrystalline diamond electrodes," Diamond and Related Materials, vol. 20, no. 1, pp. 18-22, 2011.

[110] A. F. Azevedo, N. A. Braga, F. A. Souza, J. T. Matsushima, M. R. Baldan, and N. G. Ferreira, "The effect of surface treatment on oxidation of oxalic acid at nanocrystalline diamond films," Diamond and Related Materials, vol. 19, no. 5-6, pp. 462-465, 2010.

[111] T. Clukers, B. Van Grinsven, T. Vandenryt et al., "Boron doped nanocrystalline diamond temperature regulator for sensing applications," Physica Status Solidi A, vol. 207, pp. 2110-2113, 2010.

[112] J. Zhao, D. Wu, and J. Zhi, "A direct electrochemical method for diabetes diagnosis based on as-prepared boron-doped nanocrystalline diamond thin film electrodes," Journal of Electroanalytical Chemistry, vol. 626, no. 1-2, pp. 98-102, 2009.

[113] D. Luo, L. Wu, and J. Zhi, "Fabrication of boron-doped diamond nanorod forest electrodes and their application in nonenzymatic amperometric glucose biosensing," ACS Nano, vol. 3, no. 8, pp. 2121-2128, 2009. 
[114] S. Haymond, G. T. Babcock, and G. M. Swain, "Direct electrochemistry of cytochrome $\mathrm{C}$ at nanocrystalline borondoped diamond," Journal of the American Chemical Society, vol. 124, no. 36, pp. 10634-10635, 2002.

[115] O. El Tall, N. Jaffrezic-Renault, M. Sigaud, and O. Vittori, "Anodic stripping voltammetry of heavy metals at nanocrystalline boron-doped diamond electrode," Electroanalysis, vol. 19, no. 11, pp. 1152-1159, 2007.

[116] P. Sonthalia, E. McGaw, Y. Show, and G. M. Swain, "Metal ion analysis in contaminated water samples using anodic stripping voltammetry and a nanocrystalline diamond thinfilm electrode," Analytica Chimica Acta, vol. 522, no. 1, pp. 35-44, 2004.

[117] E. A. McGaw and G. M. Swain, "A comparison of borondoped diamond thin-film and Hg-coated glassy carbon electrodes for anodic stripping voltammetric determination of heavy metal ions in aqueous media," Analytica Chimica Acta, vol. 575, no. 2, pp. 180-189, 2006.

[118] W. Yang, S. E. Baker, J. E. Butler et al., "Electrically addressable biomolecular functionalization of conductive nanocrystalline diamond thin films," Chemistry of Materials, vol. 17, no. 5, pp. 938-940, 2005.

[119] G .W. Muna, N. Tasheva, and G. M. Swain, "Electrooxidation and amperometric detection of chlorinated phenols at boron-doped diamond electrodes: a comparison of microcrystalline and nanocrystalline thin films," Environmental Science \& Technology, vol. 38, pp. 3674-3682, 2004.

[120] B. Šljukić, C. E. Banks, A. Crossley, and R. G. Compton, "Lead(IV) oxide-graphite composite electrodes: application to sensing of ammonia, nitrite and phenols," Analytica Chimica Acta, vol. 587, no. 2, pp. 240-246, 2007.

[121] M. A. Rodrigo, P. A. Michaud, I. Duo, M. Panizza, G. Cerisola, and C. Comninellis, "Oxidation of 4-chlorophenol at boron-doped diamond electrode for wastewater treatment," Journal of the Electrochemical Society, vol. 148, no. 5, pp. D60-D64, 2001.

[122] J. Iniesta, P. A. Michaud, M. Panizza, G. Cerisola, A. Aldaz, and C. Comninellis, "Electrochemical oxidation of phenol at boron-doped diamond electrode," Electrochimica Acta, vol. 46, no. 23, pp. 3573-3578, 2001.

[123] L. A. Currie, "Detection and quantification limits: basic concepts, international harmonization, and outstanding ("lowlevel”) issues," Applied Radiation and Isotopes, vol. 61, no. 23, pp. 145-149, 2004.

[124] L. Codognoto, S. A. S. Machado, and L. A. Avaca, "Square wave voltammetry on boron-doped diamond electrodes for analytical determinations," Diamond and Related Materials, vol. 11, no. 9, pp. 1670-1675, 2002. 


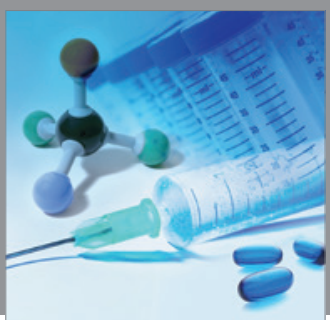

International Journal of

Medicinal Chemistry

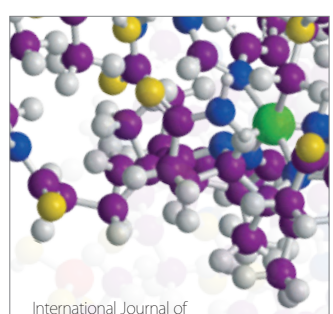

Carbohydrate Chemistry

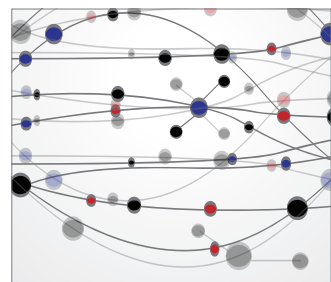

The Scientific World Journal
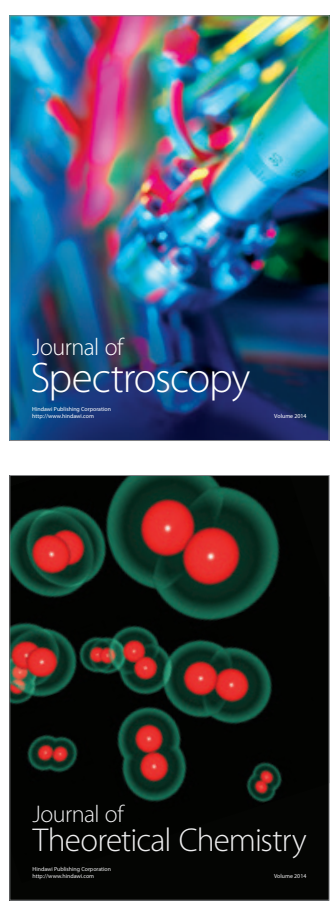
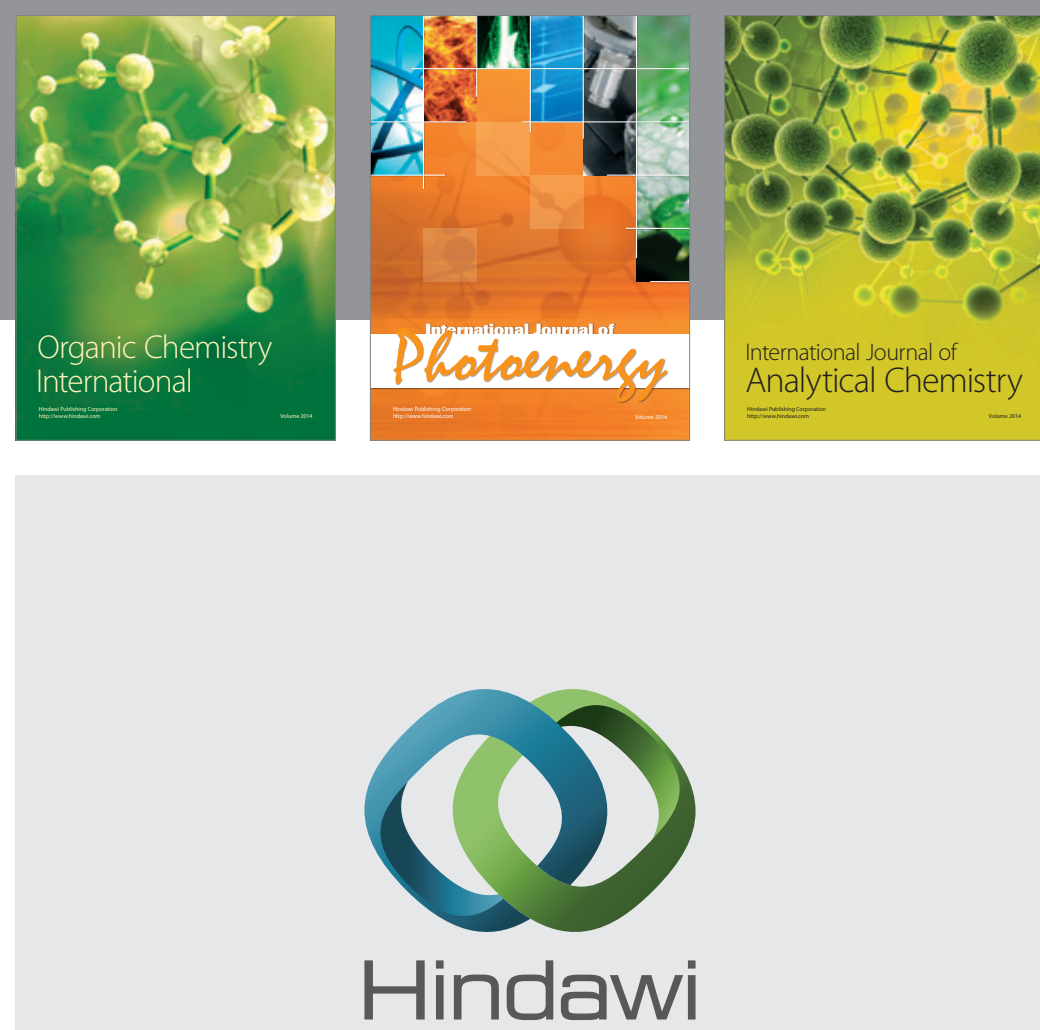

Submit your manuscripts at

http://www.hindawi.com
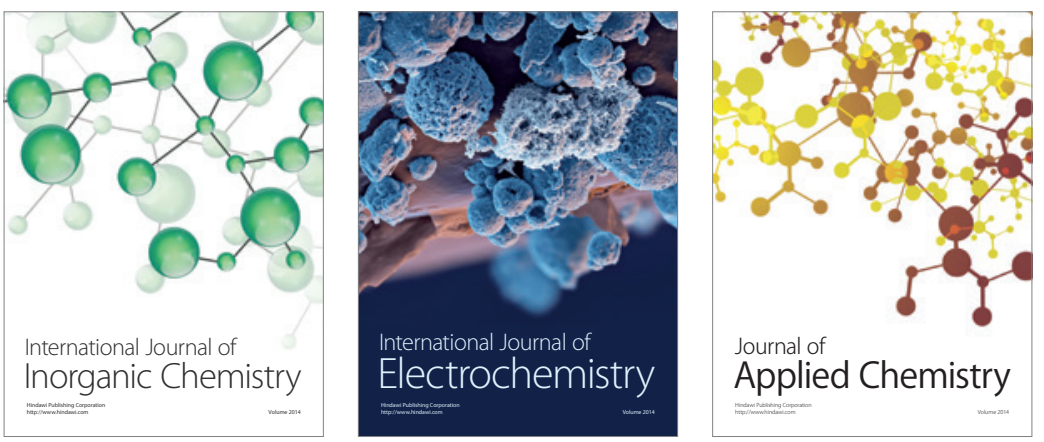

Journal of

Applied Chemistry
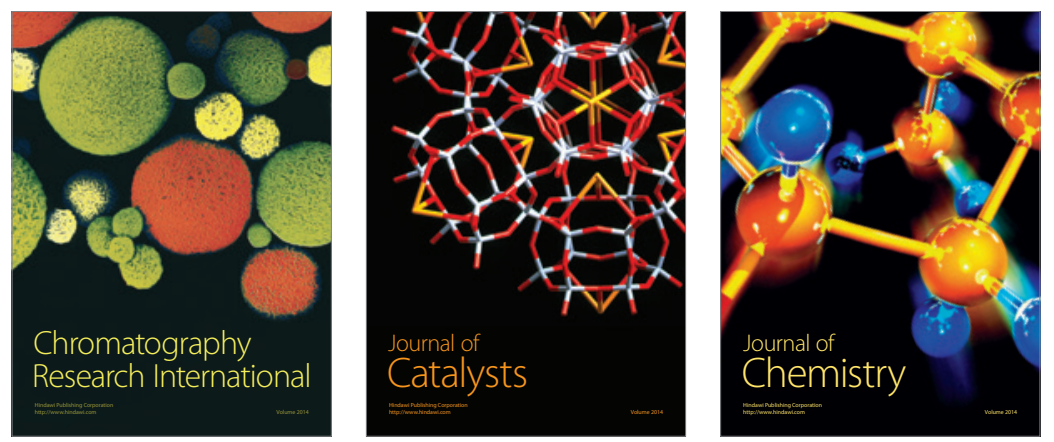
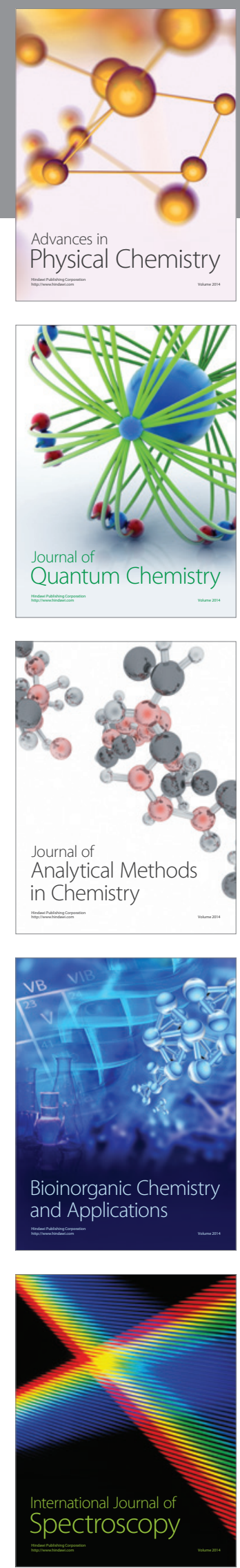